\title{
$3 \alpha$-androstanediol, but not testosterone, attenuates age-related decrements in cognitive, anxiety, and depressive behavior of male rats
}

\author{
Cheryl A. Frye (1,2,3, $^{*}$, Kassandra L. Edinger ${ }^{1}$, Edwin D. Lephart ${ }^{5}$ and Alicia A. Walf ${ }^{1}$ \\ 1 Department of Psychology, University at Albany-SUNY, Albany, NY, USA \\ 2 Department of Biological Sciences, University at Albany-SUNY, Albany, NY, USA \\ ${ }^{3}$ Center for Life Science Research, University at Albany-SUNY, Albany, NY, USA \\ ${ }^{4}$ Center for Neuroscience Research, University at Albany-SUNY, Albany, NY, USA \\ ${ }^{5}$ Department of Physiology/Developmental Biology and The Neuroscience Center, Brigham Young University, Provo, UT, USA
}

\section{Edited by:}

Thomas C. Foster, University of Florida, USA

\section{Reviewed by:}

Karyn M. Frick, Yale University, USA

Jill M. Daniel, Tulane University, USA

\section{${ }^{*}$ Correspondence:}

Cheryl A. Frye, Life Sciences Room 1058, University at Albany-SUNY,

Albany, NY 12222, USA.

e-mail: cafrye@albany.edu
Some hippocampally-influenced affective and/or cognitive processes decline with aging. The role of androgens in this process is of interest. Testosterone $(T)$ is aromatized to estrogen, and reduced to dihydrotestosterone (DHT), which is converted to $5 \alpha$-androstane, $3 \alpha, 17 \alpha$-diol (3 3 diol). To determine the extent to which some age-related decline in hippocampally-influenced behaviors may be due to androgens, we examined the effects of variation in androgen levels due to age, gonadectomy, and androgen replacement on cognitive (inhibitory avoidance, Morris water maze) and affective (defensive freezing, forced swim) behavior among young (4 months), middle-aged (13 months), and aged (24 months) male rats. Plasma and hippocampal levels of androgens were determined. In experiment 1, comparisons were made between 4-, 13-, and 24-month-old rats that were intact or gonadectomized (GDX) and administered a T-filled or empty silastic capsule. There was age-related decline in performance of the inhibitory avoidance, water maze, defensive freezing, and forced swim tasks, and hippocampal 3 $\alpha$-diol levels. Chronic, long-term (1-4 weeks) T-replacement reversed the effects of GDX in 4- and 13-month-old, but not 24-month-old, rats in the inhibitory avoidance task. Experiments 2 and 3 assessed whether acute subcutaneous T or $3 \alpha$-diol, respectively, could reverse age-associated decline in performance. $3 \alpha$-diol, but not T, compared to vehicle, improved performance in the inhibitory avoidance, water maze, forced swim, and defensive freezing tasks, irrespective of age. Thus, age is associated with a decrease in $3 \alpha$-diol production and $3 \alpha$-diol administration reinstates cognitive and affective performance of aged male rats.

Keywords: androgens, aging, testosterone, $3 \alpha$-diol, cognition, affect, depression

\section{INTRODUCTION}

The hippocampus may be a target of androgens during aging. Alzheimer's Disease (AD), associated with profound loss of declarative memory, medial temporal lobe/hippocampus degeneration, and extensive accumulation of $\beta$-amyloid, is the most common form of dementia in the elderly, and is more prevalent in women, as compared to men (Light, 1991; Howieson et al., 1993). The increased incidence, onset and severity of $\mathrm{AD}$ among women, compared to men, has largely focused on effects of estrogen deprivation (Henderson et al., 1996; Tang et al., 1996; Kawas et al., 1997). However, persons with AD (Pike and Savage, 2008), those with lesions of the hippocampus (Rosenbaum et al., 2007), and/or androgen deprivation (Freedland et al., 2009), can all experience impairments in the processes by which information is consolidated or shifted to permanent storage compared to healthy, middle-aged counterparts. Moreover, low testosterone ( $\mathrm{T}$ ) levels may be a risk factor for $\mathrm{AD}$, as some men with $\mathrm{AD}$ have lower $\mathrm{T}$ levels prior to their diagnosis than do healthy men (Hogervorst et al., 2003; Moffat et al., 2004; Raber, 2004, 2008; Pike et al., 2008; Rosario and Pike, 2008). Even normative, age-associated increases in $\beta$-amyloid can be exacerbated by T deprivation in people (Almeida et al., 2004; Sunderland et al., 2004) and male mice (Rosario et al., 2006). Together, these findings suggest that androgens may play a role in age-related, hippocampally-influenced, cognitive behavior.

Typical aging is associated with a decline in steroid hormones and cognitive and affective responses, which may be influenced by the hippocampus (Rosario et al., 2009). For example, compared to healthy, middle-aged counterparts, aged men and women experience impaired performance in tasks measuring visuo-spatial function (Clark et al., 2006), have increased self-reported feelings of depression (Butler, 2006), and exhibit increased incidence of anxiety disorders (Delhez et al., 2003). This decline occurs concomitantly with a decline in endogenous steroid hormone levels, which may influence these processes (Janowsky et al., 2000; Beer et al., 2006; Janowsky, 2006a,b). Unlike women that experience a precipitous decline in ovarian steroids with menopause (Markou et al., 2004), men experience a more gradual, decade-by-decade decline in their primary gonadal steroids, $\mathrm{T}$ and its metabolites, with aging (1.0-1.2\% per year; Janowsky, 2006a,b). Differences in endogenous $\mathrm{T}$ levels may alter cognitive and affective behav- 
ior. In support, $\mathrm{T}$ or anabolic steroid administration to healthy young men enhances verbal memory (O'Connor et al., 2001; Cherrier et al., 2002) and self-reported measures of mood and wellbeing (Cafri et al., 2006) compared to healthy young men with no exogenous androgens. Low endogenous $\mathrm{T}$ levels as a result of hypogonadism, (Howell and Shalet, 2001; Kaminetsky, 2005) or aging (Janowsky et al., 1994; Sternbach, 1998; Lund et al., 1999; Davis, 2001; Li et al., 2002; Seidman, 2003; Orengo et al., 2004; Janowsky, 2006a,b) can diminish cognitive and affective behavior, compared to their like-aged counterparts. These deficits can be reduced through T-replacement to young (Howell and Shalet, 2001; Kaminetsky, 2005) and aged (Alexander et al., 1983; Delhez et al., 2003; Janowsky, 2006a,b) men with low endogenous T levels. However, these results are not consistent across all studies (Haren et al., 2002, 2005; Delhez et al., 2003; Wolf, 2003). Although there is considerable heterogeneity in age-related cognitive and affective decline, these data suggest that decrements in some measures of cognitive and affective performance among men with low endogenous $\mathrm{T}$ levels can be reversed with T-replacement.

Animal models also illustrate T's beneficial effects on cognitive and affective behavior (as reviewed in Galea et al., 2008). In gonadally-intact rats, systemic $\mathrm{T}$ administration enhances cognitive performance in the object recognition (Ceccareli et al., 2001) task and decreases anxiety-like behavior in the elevated plus maze and Vogel punished drinking paradigm (Bitran et al., 1993; Bing et al., 1998). Gonadectomy (GDX), or removal of the primary source of male androgens, the testes, decreases cognitive performance (Ceccareli et al., 2001; Frye and Seliga, 2001; Edinger and Frye, 2004; Edinger et al., 2004; Kritzer et al., 2007; Aubele et al., 2008) and increases anxiety behavior (Bitran et al., 1993; Adler et al., 1999; Frye and Seliga, 2001; Fernandez-Guasti and Martinez-Mota, 2003) of rats across a variety of tasks. These negative effects of GDX on cognitive and affective behavior can be ameliorated, in part, through systemic T administration (Frye and Seliga, 2001; Fernandez-Guasti and Martinez-Mota, 2003; Sandstrom et al., 2006). However, some studies have found divergent and/or less robust results in studies of androgens and cognitive and affective performance (Naghdi et al., 2003; Spritzer et al., 2008; Mohaddes et al., 2009). Thus, the mechanisms for androgens' effects on these hippocampally-influenced processes are of interest, and can be investigated further in animal models.

A question is the role of T's metabolism through aging, which may account for some of the divergent effects found in studies of cognitive and affective performance of males. $T$ can be aromatized to estrogen, which has long been thought to be a mechanism through which $\mathrm{T}$ exerts beneficial behavioral effects. Estrogen can enhance cognitive and affective processes in women (Nathorst-Boos et al., 1993; Pearlstein et al., 1997; Drake et al., 2000; Sherwin, 2002) and female rats (as reviewed in Daniel et al., 1997; Frick et al., 2002; Frye and Rhodes, 2002; Daniel, 2006; Gresack and Frick, 2006; as reviewed in Palermo-Neto and Dorce, 1990; Sandstrom and Williams, 2001, 2004; Walf and Frye, 2005, 2006; Wallace et al., 2006; Luine, 2008). More recent research has looked at the effects of estrogen on age-induced memory deficits. These findings suggest that estrogen administration is more effective at restoring cognitive performance in female rodents when given in closer proximity to cessation of estrogen, whether due to ovariectomy or aging (Markowska and Savonenko, 2002; Foster et al., 2003; Savonenko and Markowska, 2003; Daniel et al., 2006; Talboom et al., 2008; Walf et al., 2009). However, there are differences in male and female response to different sex hormones (Gibbs and Johnson, 2008), which suggest that males respond more effectively to T treatment. Additionally, other studies have shown that estrogen and T may influence different types of memory (Gibbs, 2005). Finally, a study looking at the effects of estrogen on a model of $\mathrm{AD}$ in mice revealed that estrogen was not effective at preventing against $\mathrm{AD}$-induced behavioral deficits (Hunter et al., 2004). Thus, T's other routes of metabolism should be more closely examined to determine its effects and mechanisms to enhance cognitive performance.

$\mathrm{T}$ can also be reduced with the $5 \alpha$-reductase enzyme to dihydrotesterone (DHT), which is subsequently converted by $3 \alpha-$ hydroxy-steroid dehydrogenase ( $3 \alpha-\mathrm{HSD})$ to the nonaromatizable metabolite, $5 \alpha$-androstane, $17 \alpha$-diol ( $3 \alpha$-diol). $3 \alpha$-diol administration, systemically or to the hippocampus of GDX rats, enhances cognitive performance in the inhibitory avoidance, place learning, and object recognition tasks, and decreases anxiety in the elevated plus maze and open field tasks (Frye and Lacey, 2001; Frye et al., 2001; Edinger and Frye, 2004, 2005, 2007; Edinger et al., 2004). Further, blocking T's metabolism to $3 \alpha$-diol with indomethacin decreases cognitive performance and increases anxiety behavior of gonadally-intact and/or DHT-replaced rats (Frye and Edinger, 2004; Frye et al., 2004). Together, these findings suggest that T's beneficial effects on cognitive performance and affective behavior may be due, in part, to its metabolism to $3 \alpha$-diol in the hippocampus of young rodents.

The previous studies suggest that age-associated deficits in hippocampally-influenced cognitive and affective behaviors may be due to a decline in endogenous T levels, and/or T's failure to metabolize to $3 \alpha$-diol. To determine the extent to which some age-related deficits in such performance are due to T's metabolites, the effects of age-related androgen decline, gonadectomy, and androgen replacement on cognitive (inhibitory avoidance, Morris water maze) and affective (defensive freezing, forced swim) behavior among young (4 months), middle-aged (13 months), and aged ( 24 months) male rats was examined. We hypothesized that, if aging alters steroid levels, which in turn alter cognitive performance and affective behavior, that aged and GDX rats would have decreased plasma and hippocampal androgen metabolite levels, and decreased performance in cognitive and affective tasks. Furthermore, if differences in steroid metabolism mediate T's beneficial effects on cognitive performance and affective behavior, that androgen regimen that increased $3 \alpha$-diol levels in the hippocampus and plasma would enhance cognitive and affective performance. In Experiment 1, 4-, 13-, and 24-month-old rats were either left intact or GDX. GDX rats received either an empty capsule or one filled with $\mathrm{T}$ ( $\mathrm{T}$-replaced), designed to release a sustained amount of hormone over time and produce physiological levels of circulating $\mathrm{T}$ (Frye and Edinger, 2004; Frye et al., 2004). Based upon the results of Experiment 1, Experiments 2 and 3 were done, both of which utilized androgen regimen that was given acutely before affective testing or immediately after training in the inhibitory avoidance and water maze tasks to coincide with the period of memory consolidation. In 
Experiments 2 and 3, 4-, 13-, and 24-month-old rats were left intact so that the question of whether androgen-replacement to aged rats with natural decline in steroid levels could ameliorate the behavioral deficits observed with aging in Experiment 1 could be addressed. In Experiment 2, preliminary data were collected in a small group of 4-, 13-, and 24-month-old rats that were left gonadally-intact and administered subcutaneous (SC) injections of $\mathrm{T}$ or sesame oil vehicle immediately following training in the aforementioned cognitive tasks, or $1 \mathrm{~h}$ prior to testing in the anxiety and depressive tasks, to begin to ascertain timing-dependent effects of T-replacement. In Experiment 3, the responsiveness of rats to $3 \alpha$-diol was elucidated by comparing effects of administering acute, SC injections of $3 \alpha$-diol or sesame oil vehicle immediately following training in the aforementioned cognitive tasks, or $1 \mathrm{~h}$ prior to testing in the anxiety and depressive tasks. Plasma and hippocampal levels of androgens were determined, and $5 \alpha$-reductase activity was assessed in some samples to further address the role of androgen metabolism in the hippocampus for these behavioral effects. Together, the results from these experiments suggest that age is associated with a decrease in $3 \alpha$-diol production and $3 \alpha$-diol administration reinstates cognitive and affective performance of aged male rats.

\section{MATERIALS AND METHODS}

All methods used were approved by the Institutional Animal Care and Use Committee at The University at Albany-SUNY and adhered strictly to the National Institutes of Health Guide for the Care and Use of Laboratory Animals (National Institutes of Health Publications, no. 80-23, revised 1978).

\section{ANIMALS AND HOUSING}

Subjects $(N=248)$ were adult male Fisher-344 rats, which were obtained from the National Institute of Aging aged animal colony. Rats were grouped by age, such that rats that were 4 months $(n=97), 13$ months $(n=77)$, or 24 months $(n=71)$ old were included in these experiments. Experimental rats were housed two to three per cage $(45 \times 24 \times 21 \mathrm{~cm})$, which contained woodchip shavings for bedding, in a temperature-controlled room $\left(21 \pm 1^{\circ} \mathrm{C}\right)$ in the Social Sciences Laboratory Animal Care Facility at The University at Albany-SUNY. The rats lived in a 12/12-h reversed light cycle (lights off at 8:00 h) with unlimited access to Purina Rodent Chow and tap water in their home cages. All of the data from these experiments are reported, but due to attrition or health status of aged animals, group size varied across experimental tasks and neuroendocrine analyses. Initial group numbers are reported below. Separate groups of rats were used in Experiments $1(n=156), 2(n=18)$, and $3(n=71)$. Rats were handled consistently for cage cleaning and by experimenters. Specifically, rats were picked up and placed in a new cage once weekly by animal care staff in the Laboratory Animal Care Facility at The University at Albany-SUNY. In Experiment 1, rats were handled by trained experimenters for the same number of times and duration weekly for surgery or sham surgery, behavioral testing, and tissue collection. In Experiments 2 and 3, rats were handled by trained experimenters for the same number of times and duration weekly for androgen or vehicle injections, behavioral testing, and tissue collection.

\section{HORMONE MILIEU \\ Experiment 1}

Rats in each age group were randomly assigned to one of three androgen groups: intact ( 4 months, $n=22 ; 13$ months, $n=14$; 24 months, $n=14$ ), GDX ( 4 months, $n=23$; 13 months, $n=18$; 24 months, $n=15$ ), or GDX with T implants ( 4 months, $n=21$; 13 months, $n=15 ; 24$ months, $n=14)$. All rats were anesthetized with xylazine $(60 \mathrm{mg} / \mathrm{kg})$ and ketamine $(80 \mathrm{mg} / \mathrm{kg})$ for GDX $(n=106)$ or sham surgery $(n=50)$. Of these rats, some $(n=50)$ received a single silastic capsule $(1.57 \mathrm{~mm}$ inner diameter, $3.18 \mathrm{~mm}$ outer diameter) containing crystalline $\mathrm{T}$ (Sigma, St. Louis; $10 \mathrm{~mm} / \mathrm{animal}$ ) to provide a sustained amount of $\mathrm{T}$ during behavioral testing. Behavioral testing began 1 week following implantation and continued for 4 weeks following. This regimen produces physiological levels of circulating $\mathrm{T}$ (Frye and Seliga, 2001) for the duration of testing. Rats that did not receive a $\mathrm{T}$ implant received an empty silastic capsule of the same dimensions.

\section{Experiment 2}

As there were no differences between aged ( 24 months old) intact and GDX rats in Experiment 1, and previous experiments have examined the effects of T and $3 \alpha$-diol administration to GDX rats on cognitive and affective behavior (Edinger and Frye, 2004, 2005), only gonadally-intact rats were used in the subsequent studies. Using gonadally-intact rats, we were able to assess the effects of androgen decline and replacement in aging populations. In this experiment, the effects of acute $\mathrm{T}$ dosing were determined in a small group of rats. A separate group of intact rats from each age group were randomly assigned to receive a $1 \mathrm{mg} / \mathrm{kg}$ SC injection of T (4 months, $n=3 ; 13$ months, $n=3 ; 24$ months, $n=3$ ) or sesame oil vehicle ( 4 months, $n=4$; 13 months, $n=3$; 24 months, $n=2$ ) $1 \mathrm{~h}$ before testing in the anxiety tasks, and immediately following training in the cognitive tasks. This $\mathrm{T}$ regimen, when administered to young GDX rats (Edinger and Frye, 2004, 2005), or aged male mice (Frye et al., 2008), produces levels of androgens in the plasma and hippocampus that are akin to that of their young adult gonadally-intact counterparts. This regimen was used to produce physiological levels of T-replacement among aging rats. Because rats were left gondally-intact, androgen levels were assessed with these regimen.

\section{Experiment 3}

A separate group of gonadally-intact rats from each age group were randomly assigned to receive a $1 \mathrm{mg} / \mathrm{kg}$ SC injection of $3 \alpha$ diol ( 4 months, $n=12$; 13 months, $n=12 ; 24$ months, $n=11$ ) or sesame oil vehicle ( 4 months, $n=12 ; 13$ months, $n=12$; 24 months, $n=12$ ) $1 \mathrm{~h}$ before testing in the anxiety tasks, and immediately following training in the cognitive tasks. This $3 \alpha-$ diol regimen, when administered to young GDX rats (Edinger and Frye, 2004, 2005), or aged male mice (Frye et al., 2009), produces levels of androgens in the plasma and hippocampus that are akin to that of their young gonadally-intact counterparts. As in Experiment 2, this regimen was used to produce physiological levels of T-replacement among aging rats. Because rats were left gondally-intact, androgen levels were assessed with these regimen. 


\section{BEHAVIORAL TESTING}

Rats were assessed in one task (the inhibitory avoidance, defensive freezing, forced swim test, and Morris Water maze) per week over a period of 4 weeks. All rats that survived testing were assessed in each task, and rats were tested on only one occasion. Rats in each cohort and experiment were assessed in these tasks in the same order: inhibitory avoidance, water maze, defensive freezing and forced swimming test.

\section{Inhibitory avoidance}

The inhibitory avoidance task was used as per previous methods to assess hippocampally-influenced cognitive performance (Frye and McCormick, 2000b). A stainless steel box was divided into two compartments $(14 \times 18 \times 19 \mathrm{~cm}$ each $)$ with a guillotine door. One side was painted white and brightly lit from above, while the other side was painted black and covered to block light. Day One (Habituation and Training): Each rat was placed in the white chamber with their head facing the closed door and allowed to explore for 2 min. Following habituation of all animals, each rat was placed in the white chamber (with the door down) for $1 \mathrm{~min}$. The door was opened, and the latency to crossover to the dark chamber was recorded (maximum latency of $20 \mathrm{~min}$ ). The door was closed and rats received a mild shock ( $0.25 \mathrm{~mA}, 2$-s duration). Flinch-jump scores $(0=$ no response, $1=$ flinch, $2=$ movement of two paws, $3=$ jump/movement of four paws, $4=$ jump and squeak) were recorded and the means are in Table 1 . Of note, clear differences in flinch-jump scores were not noted due to age or hormone condition. Rats that did not crossover during training were excluded from data analyses. Day Two (Testing): Twenty-four hours later, rats were placed in the white chamber for $1 \mathrm{~min}$. The door was lifted and the latency to crossover to the dark side was recorded (maximum latency of $5 \mathrm{~min}$ ). Crossover latency was used as a measure of cognitive performance.

\section{Water maze}

The Morris Water Maze was used to assess hippocampallyinfluenced cognitive performance (Bennett et al., 2006). Day One (Habituation): A large circular water tank $(175 \mathrm{~cm}$ diameter, $71 \mathrm{~cm}$ deep) was filled with water $\left(20-25^{\circ} \mathrm{C}\right)$, and visually divided into four quadrants. White toxic-free tempera paint was added to the water to make it appear opaque. Rats were placed one at a time into the pool, without the platform in it, to become habituated to swimming for $1 \mathrm{~min}$ each. Day Two (Training): A clear Plexiglas platform $(5.3 \mathrm{~cm} \times 5.3 \mathrm{~cm})$ was placed in one of the quadrants, $30 \mathrm{~cm}$ from the side of the pool and $2.5 \mathrm{~cm}$ below the surface of the water. White toxic-free tempera paint was added to the water to make it appear opaque and obscure the platform. The rat was placed in one of the four quadrants of the pool and given $2 \mathrm{~min}$ to find the hidden platform on two training trials. If the rat did not find the platform, it was placed on the platform by the experimenter. The rat remained on the platform for $45 \mathrm{~s}$ after reaching it. Day Three (Testing): The pool was filled to the same height, with the platform placed in the original location in the pool. Tempera paint was added and the rat was placed into one of the quadrants. Quadrant placement was counterbalanced across four trials. The amount of time it took the animal to find the hidden platform, and the distances traveled in the maze before finding it, were considered indices of performance on Day Three. On each trial, if the rat did not find the platform, it was placed on the platform by the experimenter. The rat remained on the platform for $45 \mathrm{~s}$ after reaching it. The mean latencies for rats to reach the platform across trials is indicated in insets in Figures 1, 3, and 5 to demonstrate learning curves for rats using this measure. During both training and testing, the distances swam in the pool and the latencies were used to calculate the average swim speed in each trial.

\section{Defensive freezing}

The defensive freezing test utilized previous methods to assess anxiety in responses to a shock stimulus (Frye et al., 2000). Rats were placed in the test apparatus $(26.0 \times 21.2 \times 24.7 \mathrm{~cm})$ constructed of clear Plexiglas. An electrified probe $(2.5 \mathrm{~cm}$ in diameter, $10.0 \mathrm{~cm}$ high) was placed $3.0 \mathrm{~cm}$ from the back wall and $2.5 \mathrm{~cm}$ from the right wall of the chamber. Wood chip bedding was placed in a $5.0 \mathrm{~cm}$-deep layer, with the probe extending $4.5 \mathrm{~cm}$ above the bedding. The probe was set to deliver a single, brief, $6.66 \mathrm{~mA}$ unscrambled shock when both forepaws made contact. The shock was terminated as soon as the rat removed its paws from the probe. The response to footshock was recorded by the experimenter as a flinch-jump rating $(0=$ no response, $1=$ flinch, $2=$ movement of two paws, 3 = jump/movement of four paws, $4=$ jump and squeak). Latency to touch the probe, duration burying, and duration freezing were recorded.

\section{Forced swim test}

Previous methods for the forced swim test were utilized to assess depressive-like behavior of rats (Walf et al., 2004). Rats were placed in a cylindrical chamber $(45 \mathrm{~cm}$ high, $20 \mathrm{~cm}$ diameter) containing $30^{\circ} \mathrm{C}$ tap water to a level of $30 \mathrm{~cm}$. The time spent struggling, swimming, and immobile was recorded during the 10-min test. Immobility indicates increased depressive-like behavior.

\section{TISSUE COLLECTION}

In Experiment 1, some rats at each age and hormone condition (GDX, intact, and T-replaced) were randomly-assigned to be rapidly decapitated, trunk blood was collected, and whole brains were immediately extracted from the skull and frozen on dry ice, according to previously published methods (Frye et al., 2000). Tissue was stored at $-70^{\circ} \mathrm{C}$ until radioimmunoassay. Plasma hormone levels were measured in GDX ( 4 months, $n=12 ; 13$ months, $n=17 ; 24$ months, $n=10$ ), intact ( 4 months, $n=14 ; 13$ months, $n=16$; 24 months, $n=13$ ) and T-replaced rats (4 months, $n=7$; 13 months, $n=12 ; 24$ months, $n=6)$. The hippocampus of GDX (4 months, $n=5$; 13 months, $n=13$; 24 months, $n=9$ ), intact (4 months, $n=9$; 13 months, $n=12 ; 24$ months, $n=11$ ), and Treplaced ( 4 months, $n=5 ; 13$ months, $n=14 ; 24$ months, $n=10$ ) were assessed for steroid hormone levels and $5 \alpha$-reductase activity. In Experiment 2, rats were administered SC T (4 months, $n=4 ; 13$ months, $n=3 ; 24$ months, $n=3$ ) or vehicle (4 months, $n=3 ; 13$ months, $n=3 ; 24$ months, $n=2)$ and euthanized $1 \mathrm{~h}$ later, a time analogous to testing in the affective tasks. Similarly, in Experiment 3, a week following testing, rats were administered SC $3 \alpha$-diol ( 4 months, $n=6 ; 13$ months, $n=7 ; 24$ months, $n=7$ ) or vehicle ( 4 months, $n=6$; 13 months, $n=6$; 24 months, $n=5$ ) and euthanized $1 \mathrm{~h}$ later. Tissues were collected and stored as in 
Experiment 1. T, DHT, $3 \alpha$-diol, and estradiol $\left(\mathrm{E}_{2}\right)$ were measured by radioimmunoassay in Experiments 1 and 2, and T, DHT, and $3 \alpha$-diol were measured in Experiment 3 (as described in Frye and Bayon, 1999). Plasma corticosterone levels were also measured by radioimmunoassay in Experiment 1 (as described in Frye and Bayon, 1999). Due to limitations on animal numbers and resources, rats were randomly chosen for tissue collection from groups that survived the duration of testing, and were not included in another experiment.

\section{ANDROGEN RADIOIMMUNOASSAY}

Androgens were extracted from plasma with diethyl ether and trace amounts of ${ }^{3} \mathrm{H}$ ligand (Perkin Elmer). Brain tissue was homogenized with a glass/teflon homogenizer in distilled water. Androgens were extracted from the homogenate with diethyl ether and dried down in a savant. For plasma and brain samples, the ether was evaporated, and the pellets were reconstituted in phosphate assay buffer ( $\mathrm{pH}=7.4)$. Plasma and hippocampal concentrations of T (T3-125; Esoterix Endocrinology, Calabasas Hills, CA, 1:20,000), DHT (DT3351; Esoterix Endocrinology, 1:20,000), 3 $\alpha$-diol (X-144; Dr. PN Rao, Southwest Foundation for Biomedical Research, San Antonio, TX), and $\mathrm{E}_{2}$ (\#244; Dr. Niswender, Colorado State University, Fort Collins, $\mathrm{CO})$ were measured according to previously published methods (Frye and Bayon, 1999; Frye et al., 2008). The T and DHT assay were incubated overnight at $4^{\circ} \mathrm{C}$ and the $3 \alpha$-diol assay was incubated overnight at room temperature. The $\mathrm{E}_{2}$ assay was incubated at room temperature for $50 \mathrm{~min}$. After incubation, cold dextran-coated charcoal was rapidly added for separation of bound and free steroid. After charcoal incubation, samples were centrifuged at $3000 \times g$. The supernatant was transferred to a glass scintillation vial with scintillation cocktail (Scintiverse BD) and samples were counted. Unknowns were interpolated from the standard curve using Assay Zap, a program for radioimmunoassay analyses.

\section{CORTICOSTERONE RADIOIMMUNOASSAY}

Corticosterone was measured in a subset of samples from Experiment 1 to determine stress-mediated effects on cognitive and affective performance. Results of this experiment did not suggest that there were big group differences so corticosterone was not measured in Experiments 2 and 3. For extraction, plasma was heated to $60^{\circ} \mathrm{C}$ for $30 \mathrm{~min}$. Samples were incubated for $60 \mathrm{~min}$ at room temperature with ${ }^{3} \mathrm{H}$ corticosterone (NET 182: specific activity $=48.2 \mathrm{ci} / \mathrm{mmol}$; Perkin Elmer) and a 1:20 000 dilution of antibody (Esoterix Endocrinology:\#B3-163; Frye and Bayon, 1999). Dextran-coated charcoal was used to separate bound and free following incubation (15-min) on ice and centrifugation at $3000 \times g$ for $10 \mathrm{~min}$. Supernatant was decanted into a glass scintillation vial with scintillation cocktail and then counted. Unknowns were interpolated from the standard curve using Assay Zap.

\section{5 $\alpha$-REDUCTASE ACTIVITY}

Hippocampal tissues from a small number of subjects in Experiments 1 and 2 were assessed for $5 \alpha$-reductase activity given that results of the radioimmunoassay of these experiments suggested that there may be differences in T metabolite levels. Steroid metabolic conversion was quantified in tissue fragments from the unilateral dorsal hippocampus by thin-layer chromatography (in Dr. Edwin Lephart's laboratory, Brigham Young University). ${ }^{3} \mathrm{H}$ T was added as the substrate (at a saturating concentration of $1.75 \mu \mathrm{M}$ ) and incubated at $1 \mathrm{~h}$ at $37^{\circ} \mathrm{C}$ in Eagle's minimal essential medium (EMEM; pH 7.4; Grand Island Biological Co.) in an atmosphere of $95 \% \mathrm{O}_{2}-5 \% \mathrm{CO}_{2}$. After $1 \mathrm{~h}$, androgens were extracted using chloroform. Aliquots $(100 \mu \mathrm{l})$ of the organic-chloroform phase were evaporated to dryness, redissolved in $30 \mu$ l containing $10 \mu \mathrm{g}$ of T, DHT or $3 \alpha$-diol, and applied to silica gel, plastic sheets. The plates were developed using dichloromethane (85\%): ethyl acetate (15\%): methanol (3\%), which resolves the major $5 \alpha$-reduced metabolites from estradiol, estrone, and $5 \beta$-metabolites. Androgens were visualized by spraying with water, and the areas within each lane corresponding to the reference steroids are marked. By isolating within each lane, from the origin to the solvent front, and assaying for ${ }^{3} \mathrm{H}$, procedural losses are accounted for. The radioactivity recovered in the areas of each lane corresponding to the cold androgen standards were used to calculate activity rates which are expressed as a fraction of the total radioactivity recovered multiplied by the concentration of ${ }^{3} \mathrm{H} \mathrm{T}$ added. This revealed the enzymatic rate expressed in total $5 \alpha$-reductase activity ( $\mathrm{pmol} / \mathrm{hr} / \mathrm{mg} /$ protein; Lephart and Ojeda, 1990; Lephart et al., 1990, 2001; Table 4). Furthermore, ratios of DHT and $3 \alpha$-diol to T, and $3 \alpha$-diol to DHT, were calculated based upon radioimmunoassay results as an index of $5 \alpha$-reductase and $3 \alpha$-HSD conversion, respectively (Table 4 ).

\section{STATISTICAL ANALYSES}

Two-way analyses of variance (ANOVAs) were used to assess main effects of age (4 months, 13 months, 24 months) and androgen condition (intact, GDX, GDX $+\mathrm{T}$, intact $+3 \alpha$-diol, intact $+\mathrm{T}$ ) on behavioral and neuroendocrine measures in Experiments 1-3. Interactions between these two factors were also assessed and are reported. Where appropriate, Fisher's post hoc tests were used to assess differences between groups. The $\alpha$ level for statistical significance for main effects, interactions, and post hoc tests was a $p$-value of $<0.05$ and a trend was considered when $p=0.05-0.075$.

\section{RESULTS EXPERIMENT 1: EFFECTS OF AGING, GDX, AND CHRONIC T-REPLACEMENT ON COGNITIVE AND AFFECTIVE BEHAVIOR AND PLASMA AND/OR HIPPOCAMPUS STEROID LEVELS Inhibitory avoidance}

Training. There was a main effect of age $[F(2,135)=5.88, p<0.01$; Table 1], but not hormone condition, to increase training crossover latencies. There were no effects of either age or hormone condition on flinch-jump ratings in response to footshock during training (Table 1).

Testing. During testing, there was a main effect of age $[F(2,135)=7.2$, $p<0.01$; Figure 1A] such that $4-(p<0.01)$ and 13 -month-old $(p<0.01)$ rats had significantly longer latencies to crossover to the shock-associated chamber than did 24-month-old rats. There was also a main effect of hormone condition $[F(2,135)=9.7$, $p<0.01]$, such that GDX decreased latencies compared to intact $(p<0.01)$ and T-replaced rats $(p<0.05)$. The interaction between these variables was not statistically significant, but effects of hormone condition were most apparent in 4- and 13-, compared to 24-, month-old rats. 
Table 1 | Other measures in the inhibitory avoidance tasks of 4-, 13-, and 24-month-old gonadally-intact (intact), gonadectomized (GDX), or GDX and T-replaced (GDX $+\mathrm{T}$; Experiment 1), intact and T-administered (Experiment 2), and intact or intact or intact and $3 \alpha$-diol-administered (Experiment 3) rats. Measures are: latency to shock-associated side during training in the inhibitory avoidance task (mean \pm SEM), and flinch-jump ratings (mean $\pm S E M$ ) in response to footshock during training in this task.

\begin{tabular}{|c|c|c|c|}
\hline Age & $\begin{array}{l}\text { Steroid } \\
\text { condition }\end{array}$ & $\begin{array}{l}\text { Inhibitory } \\
\text { avoidance } \\
\text { training } \\
\text { latency (s) }\end{array}$ & $\begin{array}{l}\text { Inhibitory } \\
\text { avoidance } \\
\text { Flinch-jump } \\
\text { rating }\end{array}$ \\
\hline \multicolumn{4}{|c|}{ EXPERIMENT 1} \\
\hline \multirow[t]{3}{*}{4 Months } & Intact & $65.1 \pm 20.9 *$ & $3.4 \pm 0.3$ \\
\hline & GDX & $92.7 \pm 51.9^{*}$ & $2.8 \pm 0.3$ \\
\hline & $\mathrm{GDX}+\mathrm{T}$ & $33.6 \pm 10.3^{*}$ & $2.2 \pm 0.2$ \\
\hline \multirow[t]{3}{*}{13 Months } & Intact & $236.6 \pm 64.8$ & $2.3 \pm 0.3$ \\
\hline & GDX & $219.8 \pm 59.6$ & $2.4 \pm 0.3$ \\
\hline & $\mathrm{GDX}+\mathrm{T}$ & $126.6 \pm 27.9$ & $2.7 \pm 0.3$ \\
\hline \multirow[t]{3}{*}{24 Months } & Intact & $173.1 \pm 66.7$ & $2.7 \pm 0.4$ \\
\hline & GDX & $158.1 \pm 94.4$ & $2.2 \pm 0.2$ \\
\hline & $\mathrm{GDX}+\mathrm{T}$ & $122.6 \pm 62.1$ & $2.5 \pm 0.2$ \\
\hline \multicolumn{4}{|c|}{ EXPERIMENT 2} \\
\hline \multirow[t]{2}{*}{4 Months } & Intact & $166.7 \pm 38.9$ & $3.3 \pm 0.7$ \\
\hline & Intact $+\mathrm{T}$ & $128.5 \pm 39.5$ & $2.5 \pm 0.3$ \\
\hline \multirow[t]{2}{*}{13 Months } & Intact & $120.3 \pm 65.2$ & $1.7 \pm 0.3$ \\
\hline & Intact $+T$ & $210.3 \pm 34.4$ & $2.3 \pm 0.3$ \\
\hline \multirow[t]{2}{*}{24 Months } & Intact & $88.0 \pm 13.0$ & $3.0 \pm 1.0$ \\
\hline & Intact $+T$ & $163.3 \pm 77.9$ & $2.3 \pm 0.3$ \\
\hline \multicolumn{4}{|c|}{ EXPERIMENT 3} \\
\hline \multirow[t]{2}{*}{4 Months } & Intact & $29.4 \pm 19.9^{*}$ & $2.4 \pm 0.3$ \\
\hline & Intact $+3 \alpha$-diol & $26.1 \pm 13.2^{*}$ & $2.4 \pm 0.3$ \\
\hline \multirow[t]{2}{*}{13 Months } & Intact & $112.4 \pm 30.3$ & $3.1 \pm 0.3$ \\
\hline & Intact $+3 \alpha$-diol & $57.4 \pm 19.7$ & $2.8 \pm 0.3$ \\
\hline \multirow[t]{2}{*}{24 Months } & Intact & $20.6 \pm 4.2$ & $2.4 \pm 0.2$ \\
\hline & Intact $+3 \alpha$-diol & $72.6 \pm 31.1$ & $3.2 \pm 0.3$ \\
\hline
\end{tabular}

${ }^{*}$ Denotes significant difference from 13- or 24-month-old rats $(p<0.05)$.

\section{Water maze}

Training: There were no significant effects of age or hormone condition for latencies to the platform during training or swim speed during the two training trials (Table 2). However, there was a significant interaction between variables for distance swum in the water maze during training $[F(4,84)=3.06, p<0.02$; Table 2]. The interaction demonstrated that 13 - and 24-month-old rats that were gonadally-intact, and 13-month-old rats that were GDX and T-replaced, swam the greatest distances in the water maze during training.

Testing. There was a main effect of age for latencies $[F(2,84)=31.31, p<0.01 ;$ Figure 1B $]$ and distances swam $[F(2,84)=9.92, p<0.01$; Table 2$]$. Four-month-old rats had significantly shorter latencies to find the hidden platform on testing day compared to $13-(p<0.01)$ and 24 -month $(p<0.01)$ old rats. Four-month-old rats also swam significantly shorter distances to find the hidden platform on testing day compared to $13-(p<0.01)$ and 24 -month $(p<0.01)$ old rats. Hormone condition and age interacted for latencies $[F(4,84)=3.14$, $p=0.02]$, but not distances, such that GDX decreased latencies of 13-month-old, but not 4- or 24-month-old, intact rats. There was no significant main effect of androgen condition during testing for latencies to reach the hidden platform; however, there was a tendency for hormone condition to alter distances that rats swam to the platform $[F(2,84)=2.72, p=0.07]$, such that intact rats had longer distances than did GDX rats $(p=0.07)$. There was a main effect of age $[F(2,84)=8.62, p<0.01]$, and a tendency for an interaction between age and hormone condition $[F(4,84)=2.36, p<0.06]$, for swim speed during the testing trials, such that 4-month-old rats, particularly those that were GDX and T-replaced, had increased swim speed, compared to 13- and 24-month-old rats.

\section{Defensive freezing}

There was a main effect of age $[F(2,117)=11.38, p<0.01$; Figure $1 C]$ such that 4-month-old rats spent significantly less time freezing in response to a shock compared to $13-(p<0.01)$ or 24 -month $(p<0.01)$ old rats. Additionally, a main effect of androgen condition $[F(2,117)=3.80, p=0.02]$ illustrated that GDX increased $(p=0.05)$ time spent freezing compared to intact or T-replaced rats. Moreover, there was a significant interaction between age and androgen condition $[F(4,117)=5.42, p=0.01]$, such that GDX increased freezing in 4-, but not 13- or 24-, month-old rats, compared to intact rats or those that were T-replaced. There were no main effects of age or androgen condition or interactions between these variables for duration burying, latency to touch the electrified probe, or flinch-jump rating (Table 3).

\section{Forced swim task}

A main effect of age $[F(2,129)=51.5, p<0.01$; Figure 1D] demonstrated that 4 -month-old rats spent significantly less time immobile compared to $13-(p<0.01)$ and 24 -month $(p<0.01)$ old rats. There was also a main effect of androgen condition $[F(2,129)=22.6$, $p<0.01$ ], such that GDX increased $(p<0.01)$ immobility compared to intact or T-replaced rats. The interaction between age and hormone condition $[F(4,129)=14.4, p<0.01]$ was due to GDX increasing immobility in 4-month-old, but not 13- or 24-monthold, rats, compared to intact rats.

There was a main effect of age on time spent struggling $[F(2,129)=9.80, p<0.01 ;$ Table 3$]$ such that 4 -month-old rats spent more time struggling than $\operatorname{did} 13-(p=0.04)$ and 24 -month $(p<0.01)$ old rats. There was no effect of hormone condition on time spent struggling, or an interaction between these variables.

A main effect of age on swimming $[F(2,129=14.90, p<0.01]$ revealed more swimming among 4 -month-old rats, compared to 13 - $(p<0.01)$ and 24 -month $(p<0.01)$ old rats. There was also a main effect of androgen condition on swimming $[F(4,129)=10.45$, $p<0.01]$, such that, compared to intact rats, GDX $(p<0.01)$ rats spent significantly more time swimming. There was a significant interaction of age and androgen condition $[F(4,129)=2.02$, $p=0.02$ ], with GDX decreasing swimming in 4- and 13-, but not 24-, month-old, rats, compared to intact rats. 


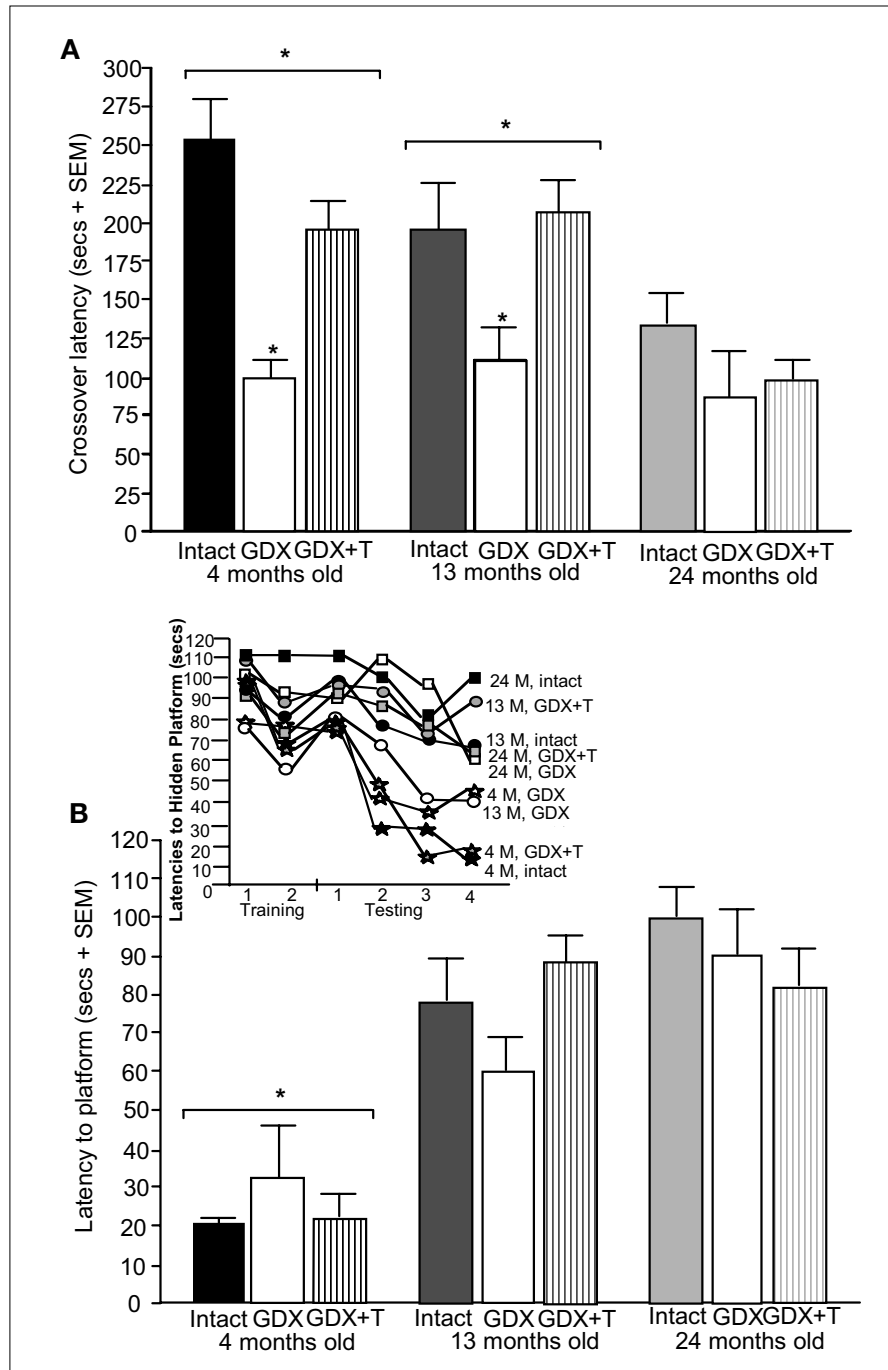

FIGURE 1 | Represents behavior of 4- (black bars), 13- (dark grey bars), and 24- (light grey bars) month-old rats that were left intact (solid bars), GDX (white bars), or GDX and T-replaced (striped bars) in the inhibitory avoidance task (A), water maze (B), defensive freezing task (C), and forced swim task (D). * over individual bars denotes
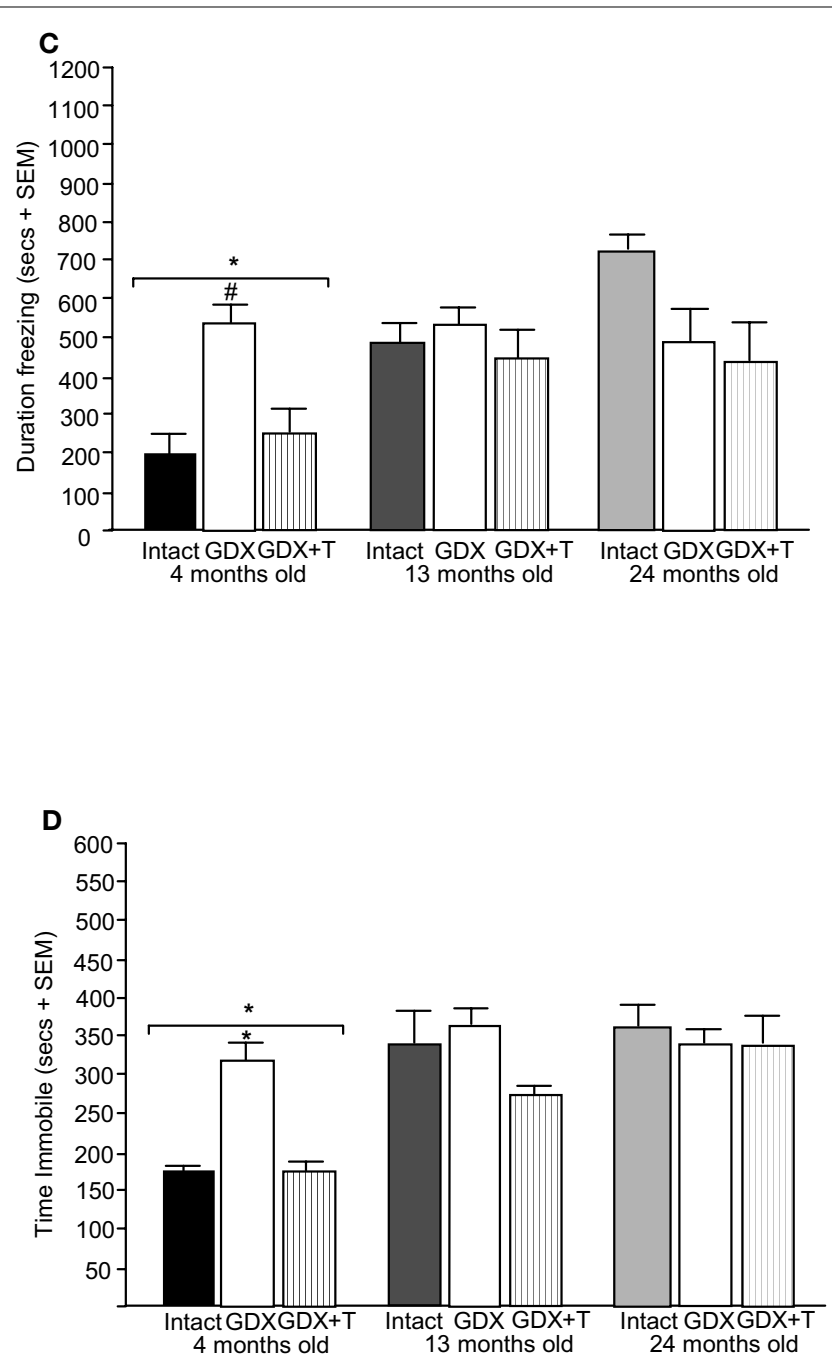

significant difference $(p<0.05)$ of GDX rats compared to intact and T-replaced rats $(p<0.05)$. \# above individual bars indicates a tendency to be different from intact rats $(p<0.075) .{ }^{*}$ over brackets denotes difference at that age group compared to age groups that do not have a bracket above bars $(p<0.05)$.

\section{Androgen and corticosterone levels (Figure 2, Tables 4 and 5)}

Age did not significantly alter plasma T levels, but there was a nonsignificant pattern for 4-month-old rats to have the highest plasma T levels than did older rats $[F(2,92)=2.48, p=0.08$; Table 4]. There was a main effect of hormone status on plasma $\mathrm{T}$ levels $[F(2,92)=4.13, p=0.02$; Table 4]. This was due to GDX decreasing plasma $(p=0.01)$ T levels, compared to intact rats, which had similar levels as those that were GDX and T-replaced. There were no significant interactions between variables for plasma $\mathrm{T}$ levels. There was a main effect of androgen condition $[F(2,92)=9.2, p<0.01]$, but not age, on $\mathrm{E}_{2}$ levels such that GDX rats had significantly lower $(p<0.01)$ plasma levels than did GDX + T-replaced rats (Table 4). Plasma DHT levels were not altered by age or hormone condition (Table 4). There was a significant main effect of age on $3 \alpha$-diol levels in plasma $[F(2,92)=20.86, p<0.01]$, such that 4 -month-old rats had significantly greater levels than 13 -month-old rats $(p<0.01)$ and 24-month-old $(p=0.01)$ rats. A main effect of androgen condition on plasma $[F(2,92)=10.21, p<0.01] 3 \alpha$-diol levels was due to GDX significantly decreasing plasma $(p<0.01) 3 \alpha$-diol levels compared to intact rats, and $\mathrm{T}$ administration reinstating plasma $(p<0.01) 3 \alpha$-diol levels similar to levels observed among intact rats (Table 4). Age and hormone condition significantly interacted for plasma $[F(4,92)=2.75, p=0.03] 3 \alpha$-diol levels, such that GDX decreased $3 \alpha$-diol levels in 4 - and 13-, but not 24-, month-old rats (Table 4). There was no effect of age or hormone status on plasma corticosterone levels (Table 4).

There was a main effect of hormone status, but not age, on hippocampal $[F(2,79)=5.4, p=0.01]$ T levels (Figure 2A). This was due to GDX decreasing hippocampal ( $p=0.04$ ) levels of T, compared to intact rats. A significant interaction of age and hormone condition $[F(4,79)=2.5, p=0.04]$ was due to GDX decreasing hippocampal $\mathrm{T}$ in 4 -month-old $(p=0.04)$, but not 13 - or 24 - 
Table 2 | Other measures in the water maze tasks of 4-, 13-, and 24-month-old gonadally-intact (intact), gonadectomized (GDX), or GDX and T-replaced (GDX $+\mathrm{T}$; Experiment 1), intact and T-administered (Experiment 2), and intact or intact or intact and 3 $\alpha$-diol-administered (Experiment 3) rats. Measures are: latency, swim speed, and distances traveled during training in the water maze (mean \pm SEM averaged over two trials) and swim speed and distances traveled during testing (mean \pm SEM averaged over four trials).

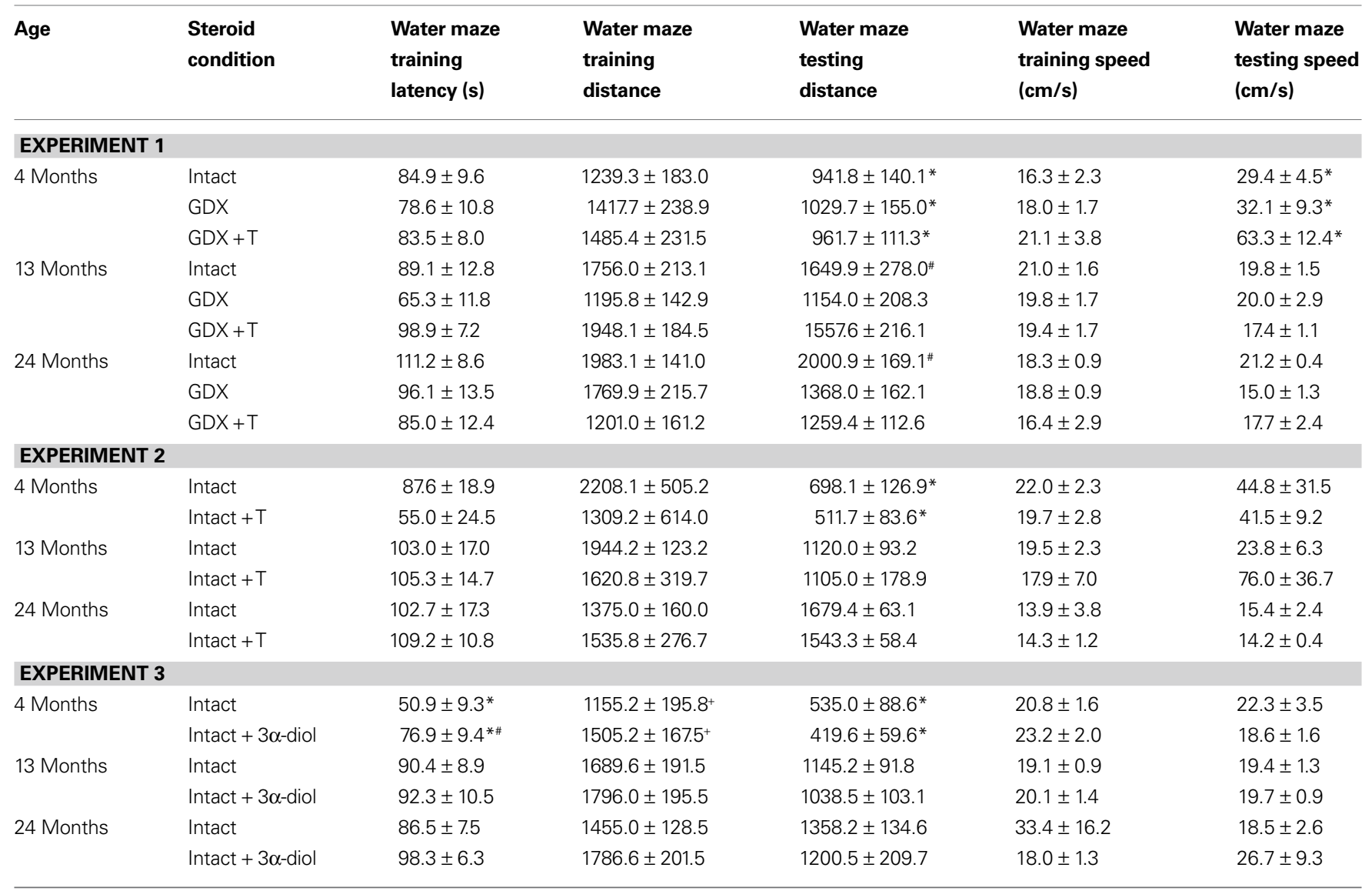

${ }^{*}$ Denotes significant difference from 13- and 24-month-old rats $(p<0.05) .{ }^{+}$Denotes trend for difference from 13 month-old rats $(p=0.5-0.75) .{ }^{*} D e n o t e s$ trend for difference from GDX or intact + vehicle $(p=0.5-0.75)$.

month-old rats. There was no main effect of androgen condition or age for hippocampal $\mathrm{E}_{2}$ (Figure 2B) or DHT (Figure 2C) levels. There was a significant main effect of age on $3 \alpha$-diol levels in the hippocampus $[F(2,79)=8.46, p<0.01]$, such that $4-(p=0.01)$ and 13- $(p<0.01)$ month-old rats had significantly greater levels than 24-month-old rats (Figure 2D). A main effect of androgen condition on hippocampal $[F(2,79)=5.15, p=0.01] 3 \alpha$-diol levels was due to GDX significantly decreasing levels compared to those observed in intact rats (Figure 2D). Age and hormone condition significantly interacted for hippocampal $[F(4,79)=4.7, p<0.01]$ $3 \alpha$-diol levels, such that GDX decreased $3 \alpha$-diol levels in 4 -, but not 13- or 24-month-old, rats (Figure 2D).

Although the analyses of conversion ratios did not reveal statistically significant differences based upon age or hormone condition for $5 \alpha$-reductase activity, intact 24 -month-old rats had the highest activity compared to other groups, and GDX, with or without Treplacement, reduced conversion (Table 5). A similar pattern was observed in the GDX and GDX + T 13- and 24-month-old groups, but effects did not reach statistical significance for $5 \alpha$-reductase activity, as measured by the thin-layer chromatography method
(Table 5). There was a trend for an effect of age on $3 \alpha-H S D$ activity, based upon conversion ratios of $3 \alpha$-diol to DHT, such that activity tended to be increased in 13-month-old rats $[F(2,79)=2.91$, $p=0.06]$ compared to 4 -month-old rats.

\section{EXPERIMENT 2: EFFECTS OF AGING AND ACUTE T-REPLACEMENT ON COGNITIVE AND AFFECTIVE BEHAVIOR AND ANDROGEN LEVELS IN CIRCULATION AND IN THE HIPPOCAMPUS Inhibitory avoidance}

Training. Age, $\mathrm{T}$ administration, or an interaction between these variables did not alter training crossover latencies, or flinch-jump responses to footshock during training (Table 1).

Testing. $\mathrm{T}$ administration did not alter crossover latencies during testing. There was a main effect of age $[F(2,12)=5.87, p=0.02$; Figure $3 \mathrm{~A}$ ], such that 4-month-old rats had significantly increased latencies to crossover to the shock-associated side of the chamber compared to 13 - ( $p=0.07)$ and 24-month $(p<0.01)$ old rats during testing trials. There were no significant interaction between these variables for crossover latencies. 
Table 3 | Motor and shock response-behavior of 4-, 13-, and 24-month-old gondally-intact (intact), gonadectomized (GDX), or GDX and T-replaced (GDX +T; Experiment 1), intact or intact and T-administered (Experiment 2), and intact or intact and $3 \alpha$-diol administered (Experiment 3) rats in the forced swim (struggling and swimming duration) and defensive freezing (Flinch/jump, latency to shock, duration burying) tasks.

\begin{tabular}{|c|c|c|c|c|c|c|}
\hline \multicolumn{2}{|c|}{ Condition } & \multicolumn{2}{|c|}{ Forced swim test } & \multicolumn{3}{|c|}{ Defensive freezing task } \\
\hline Age & Steroid condition & Struggling duration & Swimming duration & Flinch/jump & Latency to shock & Duration burying \\
\hline \multirow[t]{3}{*}{4 Months } & Intact & $167.5 \pm 9.6^{*}$ & $259.6 \pm 17.1^{*}$ & $2.0 \pm 0.3$ & $216.7 \pm 69.3$ & $141.3 \pm 38.1$ \\
\hline & GDX & $100.9 \pm 12.8^{*}$ & $161.7 \pm 11.8^{* \wedge}$ & $2.0 \pm 0.3$ & $232.8 \pm 84.9$ & $57.4 \pm 19.3$ \\
\hline & $\mathrm{GDX}+\mathrm{T}$ & $168.1 \pm 21.1^{*}$ & $266.9 \pm 16.9^{*}$ & $1.8 \pm 0.4$ & $94.5 \pm 73.3$ & $82.7 \pm 25.9$ \\
\hline \multirow{2}{*}{13 Months } & GDX & $106.1 \pm 7.8$ & $145.1 \pm 13.3^{\wedge}$ & $1.8 \pm 0.3$ & $146.1 \pm 39.8$ & $130.9 \pm 60.0$ \\
\hline & $\mathrm{GDX}+\mathrm{T}$ & $124.1 \pm 14.5$ & $209.2 \pm 17.9$ & $1.8 \pm 0.3$ & $210.0 \pm 79.4$ & $53.0 \pm 23.8$ \\
\hline \multirow[t]{3}{*}{24 Months } & Intact & $98.3 \pm 10.3$ & $150.4 \pm 17.1$ & $1.5 \pm 0.3$ & $223.6 \pm 92.4$ & $79.3 \pm 33.0$ \\
\hline & GDX & $115.4 \pm 12.1$ & $154.3 \pm 15.2$ & $2.6 \pm 0.3$ & $167.7 \pm 83.7$ & $123.7 \pm 50.7$ \\
\hline & $\mathrm{GDX}+\mathrm{T}$ & $85.5 \pm 9.6$ & $179.3 \pm 14.2$ & $2.3 \pm 0.3$ & $116.2 \pm 43.2$ & $109.3 \pm 33.2$ \\
\hline 13 Months & Intact $+T$ & $141.0 \pm 46.1$ & $242.5 \pm 32.8^{\wedge}$ & $2.3 \pm 0.3$ & $109.7 \pm 53.9$ & $167.3 \pm 91.9$ \\
\hline \multirow[t]{2}{*}{24 Months } & Intact & $110.0 \pm 23.0$ & $103.5 \pm 32.5$ & $2.5 \pm 0.5$ & $146.0 \pm 85.0$ & $0.0 \pm 0.0$ \\
\hline & Intact $+T$ & $83.0 \pm 11.1$ & $77.3 \pm 9.4^{\wedge}$ & $1.7 \pm 0.3$ & $87.3 \pm 46.5$ & $37.0 \pm 37.0$ \\
\hline \multicolumn{7}{|c|}{ EXPERIMENT 3} \\
\hline \multirow[t]{2}{*}{4 Months } & Intact & $125.4 \pm 18.5$ & $205.8 \pm 20.3$ & $1.8 \pm 0.3$ & $103.1 \pm 24.7$ & $125.8 \pm 56.2$ \\
\hline & Intact $+3 \alpha$-diol & $137.0 \pm 16.7^{\wedge}$ & $209.0 \pm 16.7$ & $1.7 \pm 0.2$ & $74.7 \pm 21.0$ & $152.3 \pm 43.7$ \\
\hline \multirow[t]{2}{*}{13 Months } & Intact & $86.8 \pm 9.2$ & $208.9 \pm 26.3$ & $2.3 \pm 0.1$ & $127.8 \pm 24.3$ & $107.9 \pm 40.0$ \\
\hline & Intact $+3 \alpha$-diol & $146.9 \pm 17.1^{\wedge}$ & $273.8 \pm 34.9$ & $1.8 \pm 0.1$ & $96.8 \pm 18.9$ & $96.5 \pm 40.6$ \\
\hline \multirow[t]{2}{*}{24 Months } & Intact & $51.1 \pm 14.8$ & $196.9 \pm 28.5$ & $1.9 \pm 0.2$ & $111.6 \pm 26.5$ & $33.4 \pm 14.8$ \\
\hline & Intact $+3 \alpha$-diol & $122.4 \pm 23.7^{\wedge}$ & $223.9 \pm 32.8$ & $1.6 \pm 0.3$ & $91.1 \pm 34.7$ & $293.5 \pm 81.8$ \\
\hline
\end{tabular}

*Denotes significant difference from 13- and 24-month-old rats $(p<0.05)$. ^Denotes significant difference from intact or intact + vehicle groups ( $p<0.05)$.

\section{Water maze}

Training. Age, T administration, or an interaction between these variables did not alter training latencies, distances swam, or swim speed during training (Table 2).

Testing. There was a main effect of age for latencies to the hidden platform $[F(2,12)=33.80, p<0.01$; Figure 3B $]$ and distances swam $[F(2,12)=34.20, p<0.01$; Table 2$]$ in the water maze during testing. Four-month-old rats, compared to $24-(p<0.01)$ and 13 -month-old rats $(p=0.01)$, had significantly decreased latencies to the platform on testing day. Compared to 24-month-old rats, 4- and 13-month-old rats swam significantly shorter distances in the water maze during testing. Neither hormone condition, nor an interaction between these variables, altered latencies or distances swam. There were no significant effects of age, hormone condition, or an interaction for swim speeds during testing (Table 2).

\section{Defensive freezing}

Hormone condition (SC T) did not alter time freezing, but there was a main effect of age $[F(2,12)=10.20, p<0.01$; Figure $3 C]$, demonstrating that $4-(p<0.01)$ and 13 -month $(p=0.01)$ old rats spent significantly less time freezing in response to shock than did 24-month-old rats. Age, hormone condition, or an interaction between these variables did not significantly alter latency to touch the probe, duration burying, or flinch-jump ratings (Table 3 ).

\section{Forced swim task}

There was no significant main effect of SC T for immobility in the forced swim test, but there was a main effect of age $[F(2,12)=6.30$, $p=0.01$; Figure 3D], such that $4-(p<0.01)$ and 13 -month $(p=0.01)$ old rats spent significantly less time immobile than did 24-month-old rats. Age and/or SC T did not alter time spent struggling. There was a main effect of age $[F(2,12)=5.24, p=0.02]$ for swimming, such that 4 - $(p=0.01)$ and 13 -month $(p=0.01)$ old rats spent more time swimming compared to 24 -month-old rats. There was also a trend for an effect of androgen condition $[F(1,12)=3.85$, $p=0.07]$, such that $\mathrm{T}$ administration $(p=0.06)$ tended to increase time spent swimming. There were no interactions of variables for any of these measures in the forced swim test.

\section{Androgen levels (Figure 4, Tables 4 and 5)}

There was a main effect of age for plasma T levels $[F(2,12)=5.93$, $p=0.01]$, such that 4 -month-old rats had significantly greater levels than did 24-month $(p=0.01)$ old rats (Table 4$)$. There was also 

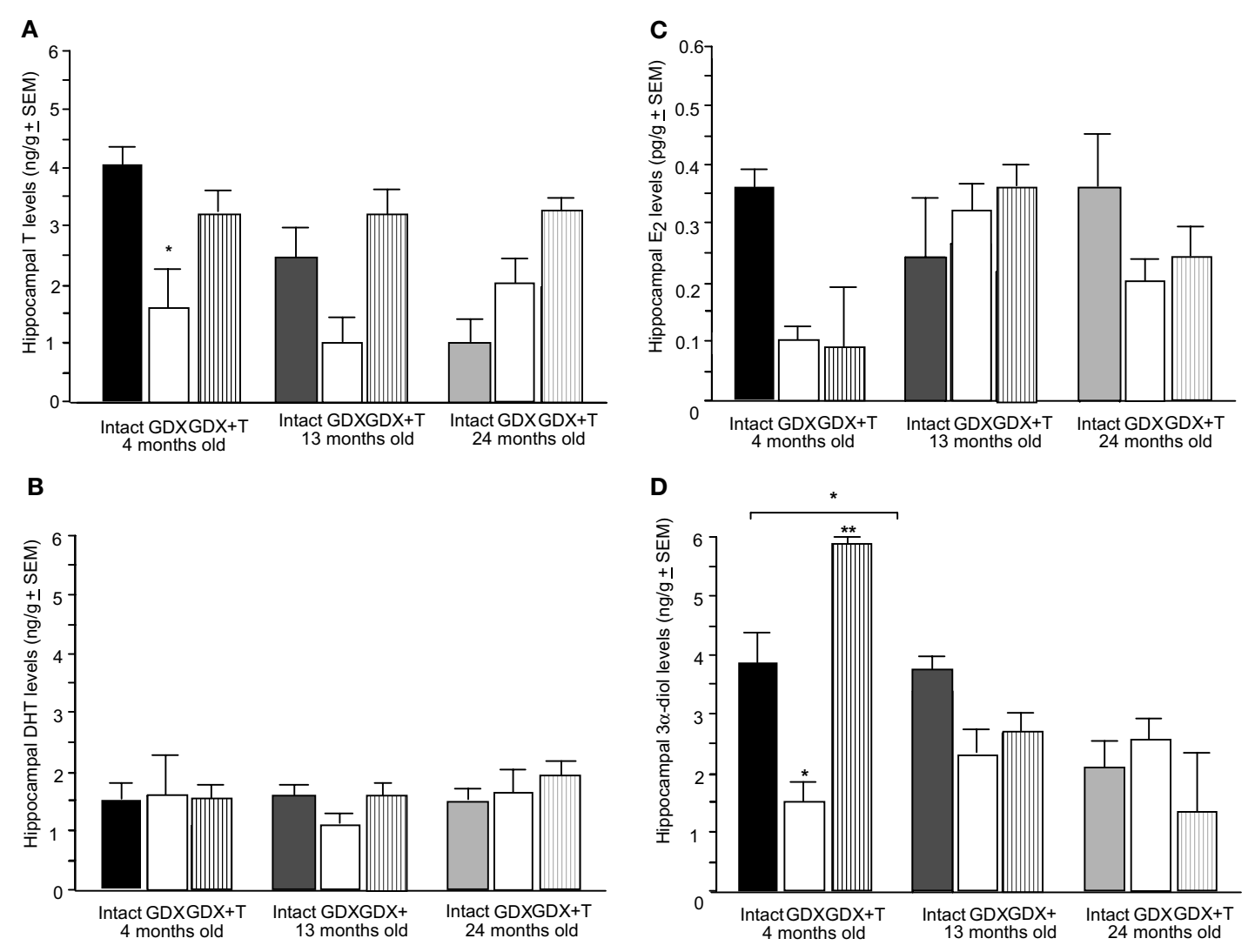

FIGURE 2 | Represents hippocampal levels of T (A), $E_{2}(B), D H T$ (C), and $3 \alpha$-diol (D) in of 4- (black bars), 13- (dark grey bars), and 24- (light grey bars) month-old rats that were left intact (solid bars), GDX (white bars), or GDX and T-replaced (striped bars). * over individual bars

denotes significant difference $(p<0.05)$ of GDX rats compared to intact rats $(p<0.05)$. ${ }^{*}$ over brackets denotes difference at that age group compared to age groups that do not have a bracket above bars $(p<0.05)$.

a main effect of androgen condition on plasma $[F(1,12)=33.8$, $p<0.01] \mathrm{T}$ levels, such that $\mathrm{T}$ administration increased levels in plasma $(p<0.01)$ compared to vehicle (Table 4$)$. There was no significant interaction between these variables for plasma $\mathrm{T}$ levels. There was no significant effect of age or $\mathrm{T}$ administration, nor an interaction, for plasma $\mathrm{E}_{2}$, DHT, or $3 \alpha$-diol levels (Table 4).

There was also a main effect of androgen condition, but not age or an interaction between these variables, on hippocampal $[F(1,12)=9.45, p=0.01] \mathrm{T}$ levels, such that $\mathrm{T}$ administration increased levels compared to vehicle ( $p=0.01$; Figure 4A). There was no significant effect of age or $\mathrm{T}$ administration on hippocampal $\mathrm{E}_{2}$ or DHT levels (Figures $4 \mathrm{~B}, \mathrm{C}$, respectively). Additionally, there was a main effect of age on hippocampal $[F(2,12)=8.36, p=0.01]$ $3 \alpha$-diol levels, such that $4-(p<0.01)$ and 13 -month $(p=0.01)$ old rats had significantly greater $3 \alpha$-diol levels compared to 24 month-old rats (Figure 4D). There was no effect of androgen condition, or an interaction between variables, on $3 \alpha$-diol levels in the hippocampus.

Age did not alter $5 \alpha$-reductase activity, but there was a main effect of androgen condition $[F(1,12)=7.39, p=0.02$ : Table 5], such that T administration $(p=0.02)$ decreased $5 \alpha$-reductase activity. Although there were no statistically significant main effects or interactions for $5 \alpha$-reductase activity measured by thin-layer chromatography, a similar pattern as seen with conversion ratios was apparent (Table 5). There were no statistically significant main effects or interactions on the conversion ratio of DHT to $3 \alpha$-diol, as a proxy of $3 \alpha-H S D$ activity (Table 5 ).

\section{EXPERIMENT 3: EFFECTS OF AGING AND ACUTE $3 \alpha$-DIOL-REPLACEMENT ON COGNITIVE AND AFFECTIVE BEHAVIOR AND ANDROGEN LEVELS IN CIRCULATION AND IN THE HIPPOCAMPUS \\ Inhibitory avoidance}

Training. There was a main effect of age on training crossover latencies $[F(2,66)=3.55, p=0.03$; Table 1] such that they were decreased in 4 -month-old rats $(p=0.01)$, but there was no main effect of hormone condition or an interaction between variables on training latencies.

Testing. There were significant main effects of age $[F(2,66)=11.49$, $p<0.01$; Figure 5A $]$ and $3 \alpha$-diol administration $[F(1,66)=11.41$, $p<0.01$ ], but not an interaction between variables, for testing crossover latencies. 4 -month-old rats had significantly higher $(p<0.01)$, and 13-month-old rats tended to have higher $(p=0.07)$, crossover latencies on testing day, compared to 24 -month-old rats. $3 \alpha$-diol increased crossover latencies compared to vehicle $(p=0.01)$. 
Table 4 | Plasma steroid levels of 4-, 13-, and 24-month-old gonadally-intact (intact), gonadectomized (GDX), or GDX and T-replaced (GDX + T; Experiment 1), intact or intact and T-administered (Experiment 2), and intact or intact and $3 \alpha$-diol administered (Experiment 3 ) rats.

\begin{tabular}{|c|c|c|c|c|c|c|}
\hline Age & Steroid condition & $T(\mathrm{ng} / \mathrm{ml})$ & $E_{2}(p g / m l)$ & DHT (ng/ml) & 3 $\alpha$-diol (ng/ml) & CORT $(\mu g / d l)$ \\
\hline \multicolumn{7}{|c|}{ EXPERIMENT 1} \\
\hline \multirow[t]{3}{*}{4 Months } & Intact & $7.0 \pm 1.1^{*}$ & $0.6 \pm 0.2$ & $3.5 \pm 0.3$ & $1.9 \pm 0.4^{*}$ & $2.9 \pm 1.3$ \\
\hline & GDX & $3.5 \pm 1.4^{* \wedge}$ & $1.2 \pm 0.4^{>}$ & $3.8 \pm 0.9$ & $0.8 \pm 0.1^{* \wedge}$ & $2.7 \pm 1.4$ \\
\hline & $\mathrm{GDX}+\mathrm{T}$ & $5.8 \pm 2.6^{*}$ & $1.0 \pm 0.4$ & $3.3 \pm 0.5$ & $1.5 \pm 0.3^{*}$ & $3.5 \pm 2.2$ \\
\hline \multirow[t]{3}{*}{13 Months } & Intact & $4.8 \pm 0.7$ & $0.7 \pm 0.2$ & $4.2 \pm 0.7$ & $1.1 \pm 0.2$ & $1.9 \pm 0.2$ \\
\hline & GDX & $2.4 \pm 0.7^{\wedge}$ & $1.0 \pm 0.4>$ & $3.5 \pm 0.5$ & $0.4 \pm 0.1^{\wedge}$ & $1.3 \pm 0.1$ \\
\hline & $\mathrm{GDX}+\mathrm{T}$ & $4.3 \pm 0.7$ & $3.2 \pm 1.1$ & $5.3 \pm 1.6$ & $1.2 \pm 0.2$ & $3.9 \pm 2.0$ \\
\hline \multirow[t]{3}{*}{24 Months } & Intact & $2.7 \pm 0.9$ & $0.4 \pm 0.1$ & $3.1 \pm 0.4$ & $0.3 \pm 0.1$ & $3.4 \pm 1.8$ \\
\hline & GDX & $2.3 \pm 0.9^{\wedge}$ & $1.4 \pm 0.8>$ & $3.3 \pm 0.9$ & $0.3 \pm 0.1$ & $3.5 \pm 2.1$ \\
\hline & $\mathrm{GDX}+\mathrm{T}$ & $5.1 \pm 1.8$ & $5.4 \pm 1.5$ & $4.8 \pm 1.4$ & $0.4 \pm 0.1$ & $1.6 \pm 0.3$ \\
\hline \multicolumn{7}{|c|}{ EXPERIMENT 2} \\
\hline \multirow[t]{2}{*}{4 Months } & Intact & $6.6 \pm 0.9^{*}$ & $1.8 \pm 0.7$ & $3.4 \pm 1.6$ & $1.4 \pm 0.1$ & - \\
\hline & Intact $+\mathrm{T}$ & $7.4 \pm 0.1^{* \wedge}$ & $1.7 \pm 0.8$ & $2.5 \pm 0.8$ & $3.0 \pm 0.8$ & - \\
\hline \multirow[t]{2}{*}{13 Months } & Intact & $5.4 \pm 0.8$ & $3.1 \pm 0.2$ & $3.2 \pm 1.4$ & $1.5 \pm 0.3$ & - \\
\hline & Intact $+\mathrm{T}$ & $7.2 \pm 0.4^{* \wedge}$ & $1.3 \pm 1.1$ & $0.8 \pm 0.0$ & $2.8 \pm 0.4$ & - \\
\hline \multirow[t]{2}{*}{24 Months } & Intact & $2.4 \pm 0.6$ & $1.3 \pm 0.1$ & $3.2 \pm 2.7$ & $0.3 \pm 0.1$ & - \\
\hline & Intact $+\mathrm{T}$ & $7.6 \pm 0.0^{* \wedge}$ & $3.2 \pm 0.2$ & $1.8 \pm 1.1$ & $0.4 \pm 0.1$ & - \\
\hline \multicolumn{7}{|c|}{ EXPERIMENT 3} \\
\hline \multirow[t]{2}{*}{4 Months } & Intact & $9.0 \pm 1.5^{* *}$ & - & $3.4 \pm 0.4$ & $1.2 \pm 0.2^{\# \#}$ & - \\
\hline & Intact $+3 \alpha$-diol & $5.4 \pm 0.4^{* *}$ & - & $3.4 \pm 0.3$ & $1.5 \pm 0.1^{\wedge \# \#}$ & - \\
\hline \multirow[t]{2}{*}{13 Months } & Intact & $5.2 \pm 1.1$ & - & $4.9 \pm 2,4$ & $1.1 \pm 0.1$ & - \\
\hline & Intact $+3 \alpha$-diol & $8.1 \pm 3.2$ & - & $5.2 \pm 2.0$ & $1.2 \pm 0.1^{\wedge}$ & - \\
\hline \multirow[t]{2}{*}{24 Months } & Intact & $2.8 \pm 0.2$ & - & $2.6 \pm 0.0$ & $0.6 \pm 0.1$ & - \\
\hline & Intact $+3 \alpha$-diol & $3.4 \pm 0.4$ & - & $4.1 \pm 0.6$ & $1.3 \pm 0.1^{\wedge}$ & - \\
\hline
\end{tabular}

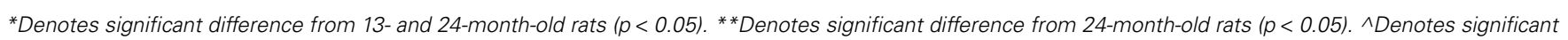

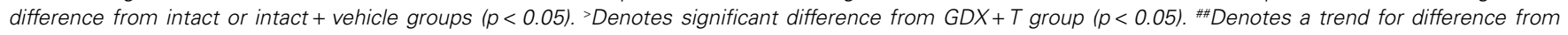
24-month-old rats $(p<0.05)$.

\section{Water maze}

Training. There was a significant main effect of age on latencies $[F(2,65)=6.80, p=0.02]$, and a trend towards significance for distances traveled to find the platform $[F(2,65)=2.77, p=0.07]$, during training. Four-month-old rats had significantly shorter latencies compared to 13- and 24-month-old rats, and tended to have shorter distances traveled compared to 13-month-old rats, during training trials. There was a trend for $3 \alpha$-diol condition to alter latencies, but not distances, during training, such that rats in the $3 \alpha$-diol group tended to have decreased latencies to find the platform during training $(p=0.07)$. There were no significant interactions for latencies or distances swam during training. There was no significant effect of age, androgen status, or an interaction between these variables for swim speed during training trials (Table 2).

Testing. There was a main effect of age on latencies $[F(2,65)=34.8$, $p<0.01$; Figure 5B] and distances traveled $[F(2,65)=24.08$, $p<0.01$; Table 2] to find the hidden platform during the testing trials, such that 4-month-old rats had significantly lower latencies and shorter distances swam than did 13- $(p<0.01)$ and 24$(p<0.01)$ month-old rats, and 13-month-old rats had significantly lower latencies and distances than did 24-month-old rats $(p=0.01$, $p<0.01)$. A main effect of androgen condition $[F(1,65)=5.32$, $p=0.02]$ was due to $3 \alpha$-diol administration significantly decreasing latencies to the platform during testing compared to vehicle $(p=0.02$; Figure 5B). There was no interaction of variables for latencies or distances, and distances were not significantly altered by androgen condition. There was no significant effect of age, androgen status, or an interaction for swim speed during testing trials (Table 2).

\section{Defensive freezing}

There was a significant main effect for age $[F(2,58)=3.99, p=0.02$; Figure 5C] in the defensive freezing task such that 4-month-old rats spent significantly less time freezing in response to shock than did 13-month-old rats $(p=0.01)$, and tended to spend less time freezing than 24 -month-old rats $(p=0.05)$. There was also a significant main effect of androgen condition $[F(1,58)=25.75, p<0.01]$. Compared to vehicle, $3 \alpha$-diol administration significantly decreased time spent freezing $(p<0.01)$. There was an interaction between age and $3 \alpha$-diol administration $[F(2,58)=3.09, p=0.05]$, such that $3 \alpha$-diol decreased time spent freezing in 13- and 24-, but not 4 month-old, rats. There was a main effect of $3 \alpha$-diol administration $[F(2,58)=5.07, p=0.02$; Table 3$]$, but not age or an interaction between variables, to increase time spent burying, compared to vehicle. Additionally, neither age, $3 \alpha$-diol administration, nor an interaction of these variables altered latency to touch the electrified probe or flinch-jump ratings (Table 3 ). 
Table 5 | $5 \alpha$-reductase activity of 4-, 13-, and 24-month-old gonadallyintact (intact), gonadectomized (GDX), or GDX and T-replaced (GDX $+\mathrm{T}$; Experiment 1) and intact or intact and T-administered (Experiment 3).

\begin{tabular}{|c|c|c|c|c|}
\hline \multicolumn{2}{|c|}{ Condition } & \multicolumn{2}{|c|}{$\begin{array}{l}\text { Conversion ratio in } \\
\text { hippocampus } \\
\text { calculated with } \\
\text { radioimmunoassay } \\
\text { results }\end{array}$} & \multirow{2}{*}{$\begin{array}{l}5 \alpha \text {-reductase } \\
\text { activity was } \\
\text { quantified by } \\
\text { thin-layer } \\
\text { chromatography } \\
5 \alpha \text {-reductase } \\
\text { activity (pmol/ } \\
\text { hr/mg protein) }\end{array}$} \\
\hline Age & $\begin{array}{l}\text { Steroid } \\
\text { condition }\end{array}$ & $\begin{array}{l}5 \alpha \text {-reduction } \\
\text { (DHT and } 3 \alpha- \\
\text { diol to } T \text { ) }\end{array}$ & 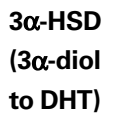 & \\
\hline \multicolumn{5}{|c|}{ EXPERIMENT 1} \\
\hline \multirow[t]{3}{*}{4 Months } & Intact & $2.1 \pm 0.5$ & $2.4 \pm 0.3$ & - \\
\hline & GDX & $3.6 \pm 1.2$ & $1.0 \pm 0.4$ & - \\
\hline & $\mathrm{GDX}+\mathrm{T}$ & $3.1 \pm 0.6$ & $3.5 \pm 0.3$ & - \\
\hline \multirow[t]{3}{*}{13 Months } & Intact & $3.9 \pm 0.9$ & $3.7 \pm 0.8^{\#}$ & - \\
\hline & GDX & $2.9 \pm 0.5$ & $2.8 \pm 0.8^{\#}$ & $1.3 \pm 0.2$ \\
\hline & $\mathrm{GDX}+\mathrm{T}$ & $2.7 \pm 0.7$ & $5.2 \pm 0.3^{\#}$ & $1.6 \pm 0.3$ \\
\hline \multirow[t]{3}{*}{24 Months } & Intact & $5.1 \pm 1.3$ & $2.1 \pm 0.5$ & - \\
\hline & GDX & $3.1 \pm 1.1$ & $2.3 \pm 0.6$ & $1.7 \pm 0$ \\
\hline & $\mathrm{GDX}+\mathrm{T}$ & $1.7 \pm 0.6$ & $0.9 \pm 0.4$ & $1.5 \pm 0.4$ \\
\hline \multicolumn{5}{|c|}{ EXPERIMENT 2} \\
\hline \multirow[t]{2}{*}{4 Months } & Intact & $1.6 \pm 0.1$ & $5.0 \pm 2.6$ & $0.8 \pm 0.1$ \\
\hline & Intact $+T$ & $1.2 \pm 0.2^{\wedge}$ & $2.5 \pm 1.1$ & $1.1 \pm 0.2$ \\
\hline \multirow[t]{2}{*}{13 Months } & Intact & $4.3 \pm 2.9$ & $2.3 \pm 0.2$ & $1.3 \pm 0.2$ \\
\hline & Intact $+\mathrm{T}$ & $1.3 \pm 0.4^{\wedge}$ & $2.4 \pm 1.1$ & $0.9 \pm 0.1$ \\
\hline \multirow[t]{2}{*}{24 Months } & Intact & $6.8 \pm 3.3$ & $1.9 \pm 1.3$ & $1.5 \pm 0.7$ \\
\hline & Intact $+T$ & $0.5 \pm 0.4^{\wedge}$ & $0.4 \pm 0.1$ & $1.1 \pm 0.2$ \\
\hline
\end{tabular}

$\wedge$ Denotes significant difference from intact + vehicle group $(p<0.05)$. "Denotes trend to be different from 4- and 24-month-old rats $(p=0.5-0.75)$.

\section{Forced swim task}

There was no main effect of age for immobility in the forced swim test (Figure 5D), but the pattern of effects suggest that 4and 13-month-old rats spent less time immobile compared to 24-month-old rats. There was a main effect for androgen status $[F(1,57)=27.25, p<0.01]$, such that $3 \alpha$-diol administration significantly decreased immobility compared to vehicle administration $(p<0.01$; Figure 5D). The significant interaction between age and hormone condition $[F(2,57)=4.12, p=0.02]$, was due to the fact that $3 \alpha$-diol was more effective at decreasing immobility in 13- and 24-, rather than 4-, month-old intact rats $[F(2,57)=3.22, p=0.04$; Table 2$]$. There was a main effect of androgen condition $[F(2,57)=11.6, p=0.04]$, but not age or an interaction, for struggling due to $3 \alpha$-diol administration increasing time struggling compared to vehicle $(p=0.02)$. There was no effect of age or $3 \alpha$-diol administration, or an interaction, on time spent swimming.

\section{Androgen levels (Figure 6, Table 3)}

There was a main effect of age, but not $3 \alpha$-diol administration or an interaction, such that 4-month-old rats had increased plasma T levels $[F(2,30)=4.05, p=0.03]$ compared to 24 -month-old rats $(p=0.02) .3 \alpha$-diol administration did not alter plasma or hippocampal DHT. There were no effects of age, $3 \alpha$-diol administration, or an interaction for plasma DHT levels. A trend towards a main effect of age $[F(1,30)=2.95, p=0.07]$ was due 4-month-old rats tending to have increased plasma $3 \alpha$-diol levels compared to 24 -monthold rats $(p=0.01) .3 \alpha$-diol administration significantly increased $3 \alpha$-diol in plasma $[F(1,30)=11.14, p<0.01]$ compared to vehicle control $(p<0.01)$. There was a trend for an interaction of age and $3 \alpha$-diol condition for plasma $[F(2,30)=2.74, p=0.07] 3 \alpha$-diol levels, such that levels were increased in 13- and 24-month-old, but not 4-month-old, rats.

There was a main effect of age, but not androgen administration or an interaction, for hippocampal $[F(2,30)=54.8, p<0.01] \mathrm{T}$ levels, such that 4-month-old rats had increased T levels compared to 13 - $(p<0.01)$ and 24 -month-old $(p<0.01)$ rats (Figure 6A). There was also a main effect of age, but not androgen administration or an interaction, on DHT levels, such that 4-month-old rats had increased hippocampal $[F(2,30)=54.8, p<0.01]$ DHT levels compared to 13- $(p<0.01)$ and 24-month-old $(p<0.01)$ rats (Figure 6B). $3 \alpha$-diol administration significantly increased $3 \alpha$-diol in the hippocampus $[F(1,30)=43.7, p<0.01]$ compared to vehicle control $(p<0.01 ; p<0.01$; Figure 6C). There was a significant interaction for hippocampal $[F(2,30)=11.8, p<0.01]$ levels, such that $3 \alpha$-diol levels were increased in 13- and 24-month-old, but not 4-month-old, rats.

\section{DISCUSSION}

Our findings support the hypothesis that aged rats would have decreased plasma and hippocampal androgen levels, and that androgen regimen that increased plasma $3 \alpha$-diol would enhance cognitive and affective behavior of rats with decreased steroid levels due to GDX or aging. In support, in most experiments, 4month-old rats had better performance than aged counterparts as evidenced by increased crossover latencies in the inhibitory avoidance task, decreased latencies to find the platform in the water maze task, decreased depressive behavior in the forced swim task, and decreased freezing in the defensive freezing task. Gonadectomy decreased performance in these tasks, with reversals of these effects with chronic $\mathrm{T}$ replacement, which was most apparent among 4-, compared to 13- or 24-, month-old rats. Furthermore, acute administration of $3 \alpha$-diol, but not $\mathrm{T}$, improved performance across tasks in aged rats. Notably, age decreased $3 \alpha$-diol in plasma and the hippocampus such that 13-month-old rats had significantly greater levels than 24-month-old rats, and 4-month-old rats had significantly greater levels than 13-month-old rats. Additionally, $\mathrm{T}$ replacement to 4-month-old, but not 13- or 24-month-old, GDX rats increased plasma and hippocampal $3 \alpha$-diol levels. These findings suggest that age-associated deficits in cognitive and affective performance may be related to $3 \alpha$-diol metabolism in the hippocampus.

The results of the present experiment confirm previous reports on the effects of aging on behavioral and neuroendocrine processes of male rats, and the potential role of androgen replacement. Aged rats are typically impaired in comparison to younger rats on both working and reference memory components of spatial tasks, such as the water maze (Barnes, 1979; Gage et al., 1988; Gallagher and Burwell, 1989; Ando and Ohashi, 1991; Gallagher and Nicolle, 1993; Colombo and Gallagher, 1998). Differences have been observed among Fischer 344 rats beginning at middle-age 
A
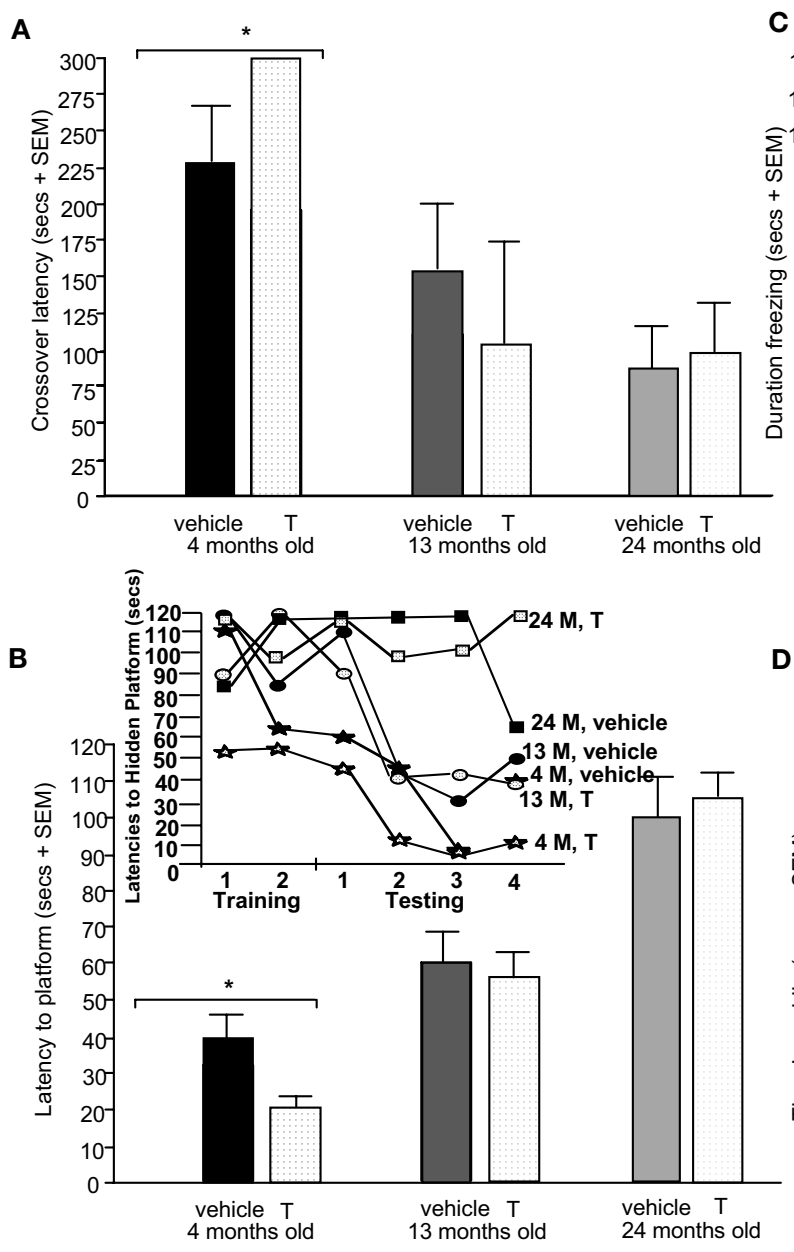

C

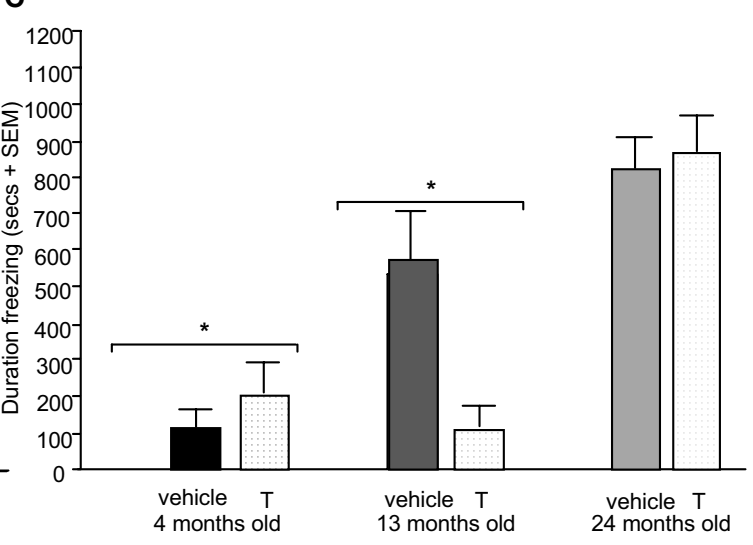

D

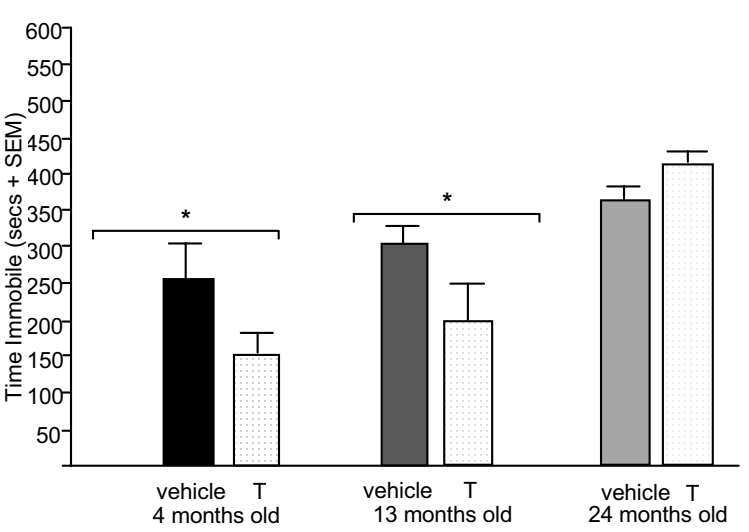

FIGURE 3 | Represents behavior of 4- (black bars), 13- (dark grey bars), and 24- (light grey bars) month-old intact rats administered subcutaneous injections of sesame oil vehicle (solid bars) or T (stippled bars) in the inhibitory avoidance task (A), water maze (B), defensive freezing task (C), and forced swim task (D). ${ }^{*}$ over brackets denotes difference at that age group compared to age groups that do not have a bracket above bars $(p<0.05)$. (i.e. approximately $12-15$ months of age; Shukitt-Hale et al., 1998) when compared to young adult rats (6 months of age). In another strain, Fischer $344 \times$ Brown Norway hybrid, middle-aged (13 months old) had similar performance deficits in a retention trial in the water maze as did 24-month-old rats, compared to 3month-old rats (Driscoll et al., 2006). We found that 4-month-old rats outperformed their older counterparts in the water maze in the present series of experiments. Additionally, similar to what was observed in the inhibitory avoidance task in the present study, aged (30 months old) male Fischer-344/Brown-Norway had poorer performance than their younger counterparts (3-and 15-month olds) for fear conditioning (Kasckow et al., 2005). Fewer studies have compared affective behavior of young versus middle-aged versus aged male rats. In one study, no differences were observed in the forced swim test in aged compared to younger Fischer-344/Brown Norway rats (Kasckow et al., 2005). In another study, restraint stress decreased anxiety-like responding of middle-aged and aged Fischer-344 rats, which were 12- and 24-month-old, respectively, compared to 4-month-old rats in the elevated plus maze (Pisarska et al., 2000). In the present study, 4-month-old Fischer-344 rats demonstrated less anxiety in the defensive freezing task, and more depression-like behavior in a one-trial forced swimming task. The present study confirms previous reports on stress hormone and androgen levels with aging in male rats. For instance, similar to what was found in Experiment 1 of the present study, in a hybrid strain of male Fischer-344/Brown-Norway, no differences were observed in basal plasma corticosterone levels when rats were assessed during young adulthood ( 3 months old), middle-age ( 15 months old), and late age ( 30 months old) (Kasckow et al., 2005). Androgen levels of male rats begin to decline at middleage, at around 13 months old, and salient decreases are noticed when rats are around 24 months old (Gray, 1978; Chambers and Phoenix, 1984) and we observed similar age-related decline in T and $3 \alpha$-diol levels in the present study. A question is the capacity for rats to respond to androgen-replacement with aging, but few studies have examined the effects of androgen-replacement to older rats. In one study, T, but not DHT, administration enhanced water radial arm maze performance of 23-month-old male rats (Bimonte-Nelson et al., 2003). However, in another investigation, T did not improve Morris Water maze performance in 31-month-old 


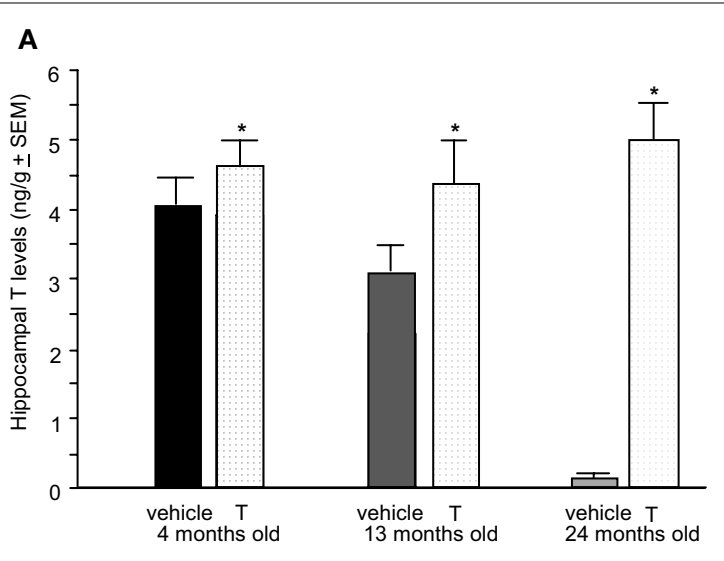

B

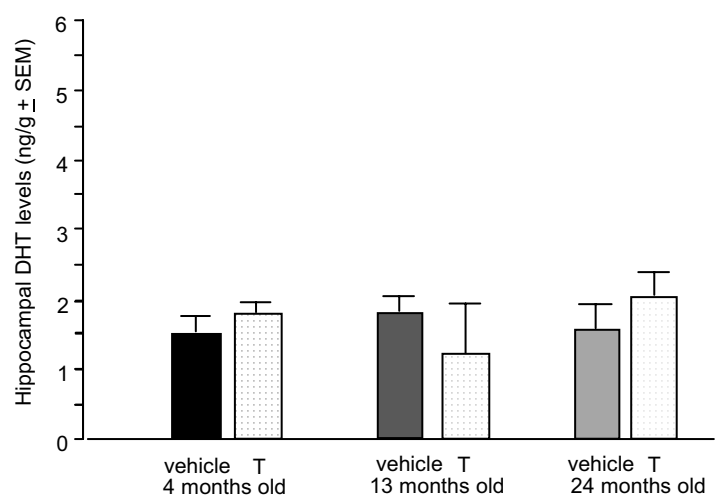

FIGURE 4 | Represents hippocampal levels of T (A), $E_{2}$ (B), DHT (C), and $3 \alpha$-diol (D) in - (black bars), 13- (dark grey bars), and 24- (light grey bars) month-old intact rats administered subcutaneous injections of sesame oil vehicle (solid bars) orT (stippled bars).

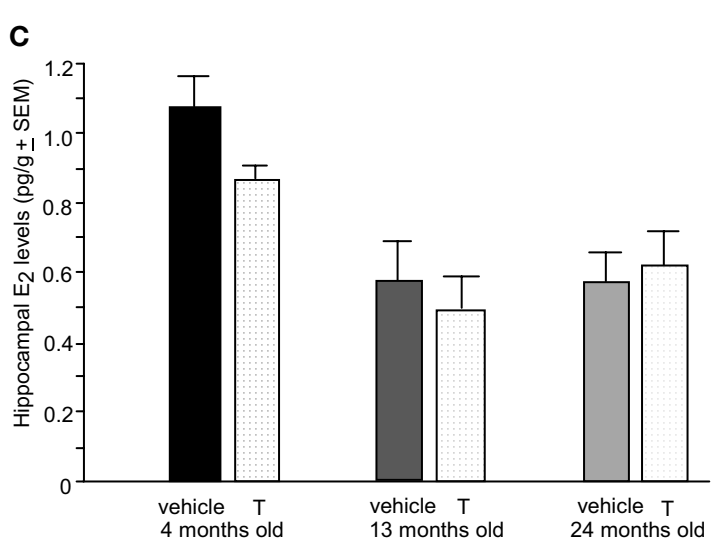

D

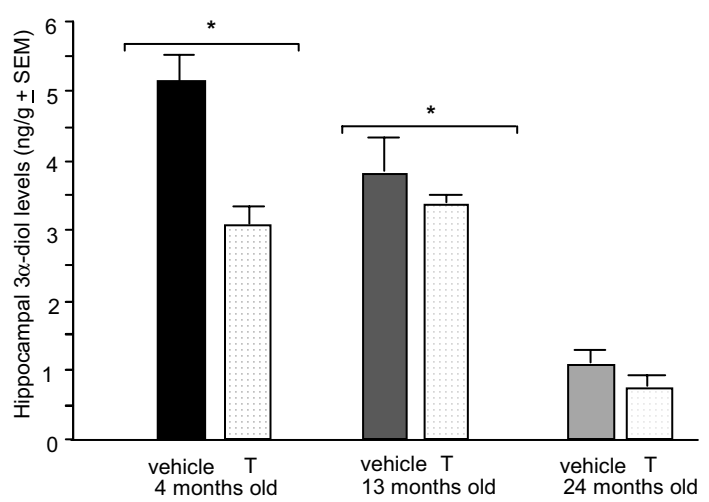

* Over individual bars denotes significant difference $(p<0.05)$ of T-administration over vehicle $(p<0.05)$. ${ }^{*}$ Over brackets denotes difference at that age group compared to age groups that do not have bracket above bars $(p<0.05)$. rats (Goudsmit et al., 1990). One interpretation of these findings and the present results is that $\mathrm{T}$ may have limited effects to improve performance as rodents age, but the mechanisms for these effects require further investigation.

The present results confirm previous reports on the effects of gonadectomy and androgem administration. The findings from Experiment 1 support previous findings that GDX can induce behavioral deficits in measures of cognitive and affective performance (Bing et al., 1998; Ceccareli et al., 2001; Edinger and Frye, 2004; Frye et al., 2009). The findings in Experiments 2 and 3 , that androgen administration to intact rats can enhance cognitive and affective behavior, is also consistent with previous studies of cognitive performance (Ceccareli et al., 2001) and anxiety-like behavior (Bitran et al., 1993) illustrating that T administration to intact rats enhances these behaviors. The present data also support previous studies suggesting that $5 \alpha$-reduced metabolites are important for T's positive effects on cognitive and affective behavior. For example, previous findings indicate that administration of $\mathrm{T}$ and its $5 \alpha$-reduced metabolite, $3 \alpha$-diol, to young, GDX, rats significantly enhances cognitive and affective performance (Frye and Seliga, 2001; Edinger and Frye, 2004, 2005; Edinger et al., 2004). In support, the present findings indicate that administration of $\mathrm{T}$ or
$3 \alpha$-diol to young, gonadally-intact, or young, GDX rats enhances performance in the inhibitory avoidance and water maze tasks, similarly decreases anxiety-like behavior in the forced swim and defensive freezing tasks.

The present data also support previous studies indicating that androgens' beneficial effects on cognitive and affective performance may be due in part to actions in the hippocampus. Indeed, it has been proposed that there is a relationship between impaired inhibitory avoidance and water maze performance and induction to long-term depression in hippocampal slices (Foster and Kumar, 2007). Although we did not directly manipulate androgen action in the hippocampus in the present study, the present results confirm findings of prior studies in young rats that have had androgens' actions manipulated in the hippocampus. In support, androgen administration directly to the hippocampus of GDX rats produces beneficial effects on cognitive and affective behavior similar to that found in GDX rats administered systemic androgens (Edinger and Frye, 2004, 2005; Edinger et al., 2004). In the present study, behavior in the hippocampally-influenced water maze and inhibitory avoidance tasks was enhanced through androgen administration. Further, systemic administration of T and/or $3 \alpha$-diol significantly increased $3 \alpha$-diol levels in the hippocampus. Notably, only andro- 

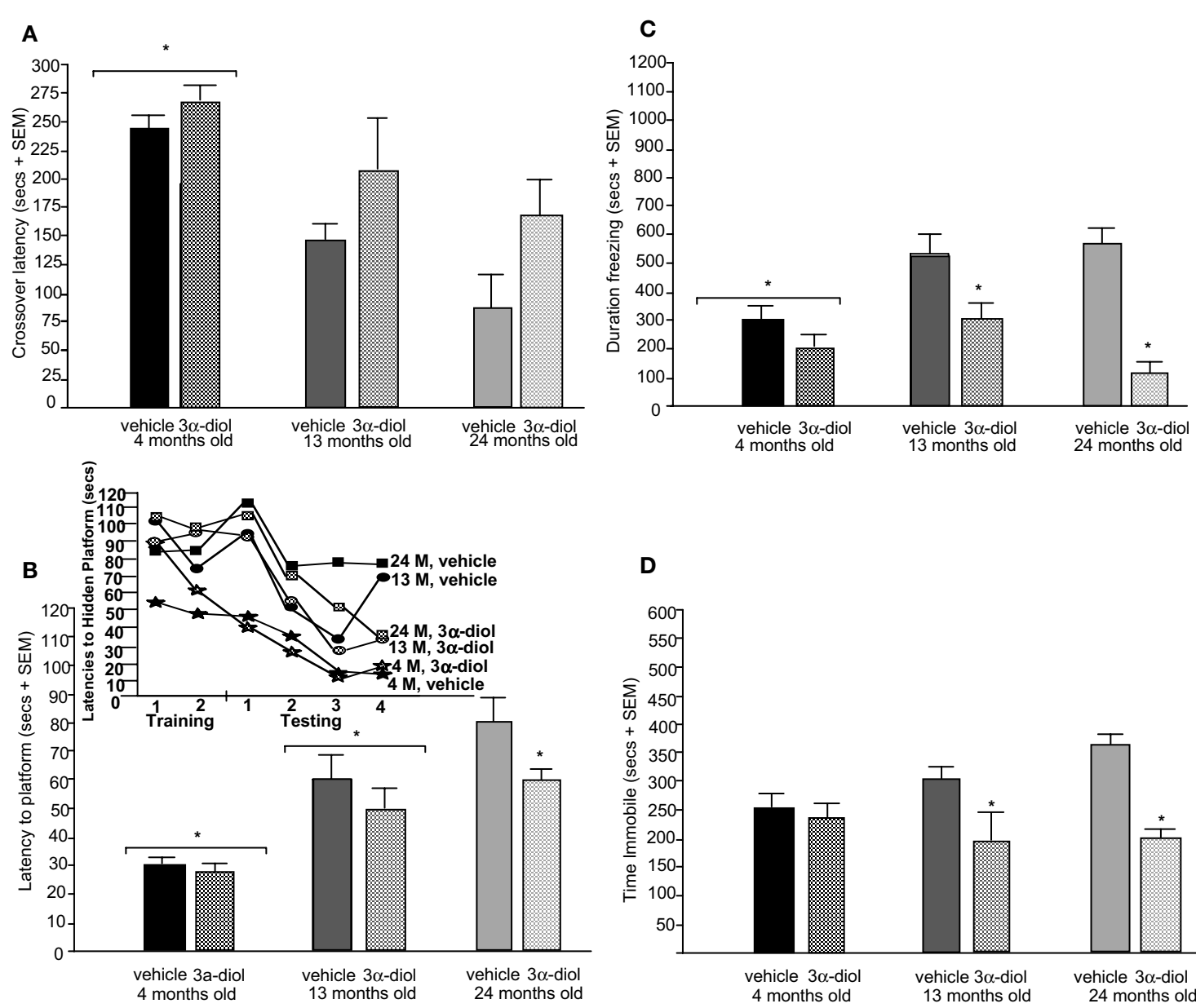

FIGURE 5 |Represents behavior of 4- (black bars), 13- (dark grey bars), and 24-(light grey bars) month-old intact rats administered subcutaneous injections of sesame oil vehicle (solid bars) or $3 \alpha$-diol (checkered bars) in the inhibitory avoidance task (A), water maze (B), defensive freezing task (C), and

gen regimens that increased hippocampal $3 \alpha$-diol levels were consistently effective at enhancing cognitive and affective behaviors in these and the present studies. The present data are also consistent with previous experiments in gonadally-intact aged male mice indicating that administration of $\mathrm{T}$ or $3 \alpha$-diol enhances performance in the inhibitory avoidance and conditioned contextual fear tasks, decreases anxiety behavior in the open field, light-dark transition, mirror maze, and elevated plus maze tasks, and decreases depressive behavior in the forced swim task (Frye et al., 2008). Testosterone administration did not consistently enhance behavior in the present study. However, in this previous study in mice, $\mathrm{T}$ administration was effective at enhancing cognitive and affective behavior and at elevating hippocampal $3 \alpha$-diol levels among aged mice. In the present study, T administration did not consistently increase hippocampal $3 \alpha$-diol levels among aged rats. Thus, these differences in behavioral outcomes may be due to differences in metabolism. It is important to note that the present study looked at the effects of peripheral, not central, androgen administration. A question for future studies would be the extent to which other brain regions may be targets for androgens to influence cognitive and affective behav-

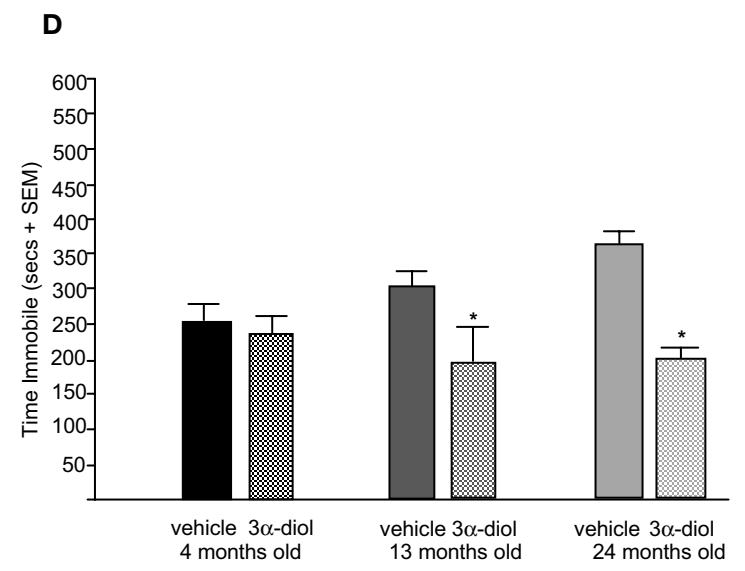

forced swim task (D). * Denotes significant difference of $3 \alpha$-diol administration compared to vehicle $(p<0.05)$. "Denotes tendency for differences of 13-month-old rats to 24 -month-old rats $(p<0.075) .{ }^{*}$ Over brackets denotes difference at that age group compared to age groups that do not have bracket above bars $(p<0.05)$.

ior and the role of direct manipulation of androgens in the hippocampus, and other brain regions, among aged rodents. Together, these data suggest that age-associated deficits in performance of hippocampally-influenced tasks may be due to actions of T's $5 \alpha$ reduced metabolite, $3 \alpha$-diol, in the hippocampus.

The present findings extend previous studies suggesting that androgen decline with aging produces cognitive and affective deficits that can be ameliorated through androgen replacement. Investigations of aging in female rodents indicate that aging results in deficits in cognitive and affective performance that can be reduced through administration of T's aromatized metabolite, estrogen (Frick et al., 2002; Markham et al., 2002; Gresack and Frick, 2006; Walf et al., 2009; Walf and Frye, 2010), or progesterone (Frye and Walf, 2009). Although the effects of androgens and aging on cognitive and affective performance have been less thoroughly studied, previous findings indicate that $\mathrm{T}$ and DHT to aged female mice can enhance cognitive performance in the water maze (Benice and Raber, 2009). Aged, 24-month-old male and female mice respond similarly to T, $\mathrm{E}_{2}$, DHT, or $3 \alpha$-diol to produce decreased immobility in the forced swim test (Frye and 


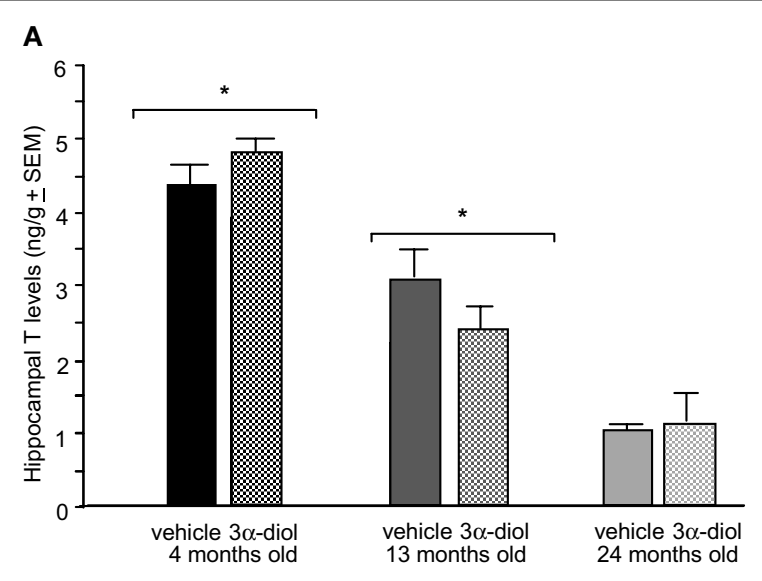

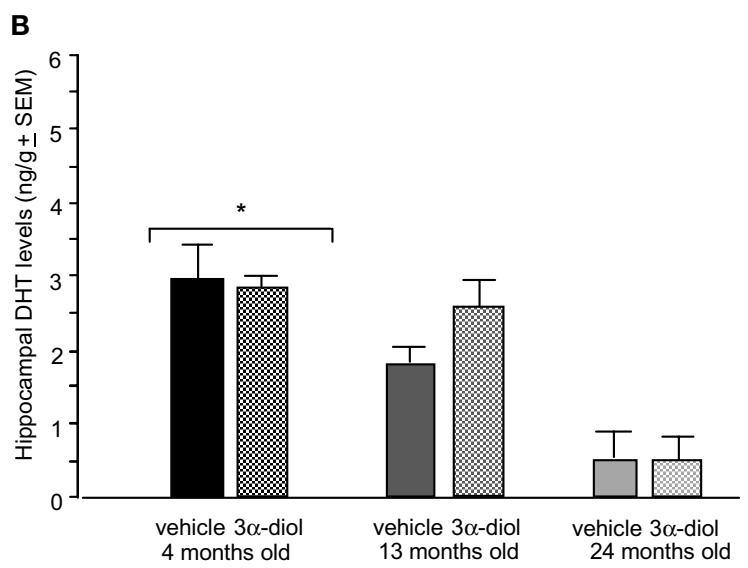

FIGURE 6 | Represents hippocampal levels of T (A), DHT (B), and $3 \alpha$-diol (C) of 4- (black bars), 13- (dark grey bars), and 24- (light grey bars) month-old gonadally-intact rats administered subcutaneous injections of sesame oil vehicle (solid bars) or $\mathbf{3} \alpha$-diol (checkered bars). * Denotes

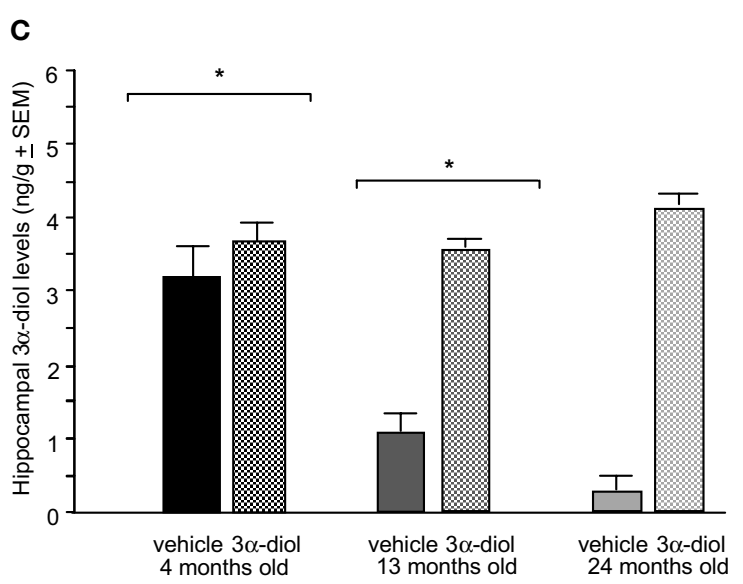

significant difference of $3 \alpha$-diol administration compared to vehicle $(p<0.05)$. \#Denotes tendency for differences of 13-month-old rats to 24-month-old rats $(p<0.075) .{ }^{*}$ Over brackets denotes difference at that age group compared to age groups that do not have bracket above bars $(p<0.05)$.
Walf, 2009). As previously mentioned, systemic administration of $\mathrm{T}$ or $3 \alpha$-diol to aged male mice enhances cognitive performance, decreases depressive behavior, and decreases anxiety behavior, compared to vehicle administration (Frye et al., 2008). The present study extends these findings to aged male rats and suggests that androgen administration can enhance age-associated deficits in cognitive and affective performance, only when $3 \alpha$-diol is increased. In support, administration of $3 \alpha$-diol, but not T, consistently enhanced behavior of rats in the water maze, inhibitory avoidance, forced swim, and defensive freezing tasks, in the present study. Further, $3 \alpha$-diol was the only androgen that was consistently elevated in the hippocampus at the time of tissue collection among rats that displayed enhanced behavior. Given the design of the present experiments and that behavioral assessments were done at different points following androgen administration, it was not possible to determine whether androgen levels were correlated with behavior. The present results support further investigation of this question directly in the future. Finally, we had some evidence that $5 \alpha$-reductase activity was altered by age and androgen condition, suggesting that older rats may have increased activity and therefore less $3 \alpha$-diol in the hippocampus due to increased back-conversion to T or DHT. Of interest is whether aged rats had differences in expression of these metabolism enzymes in the hippocampus. In AD patients, steroid metabolism enzymes are increased and positively-related to poorer cognitive function (Schaeffer et al., 2006). Notably, aging and/or androgen deprivation are associated with increased levels of cholesterol (Spinar et al., 2009; Traish et al., 2009), which may increase enzyme activity (Pettersson et al., 2009). Given high variability, and low sample size, it would be of interest to more systematically examine the activity and expression of these metabolism enzymes, and their relation to cholesterol levels, in aged male rats in a future study. Together, these data suggest that aging can result in deficits in cognitive and affective performance that may be due to decreased $3 \alpha$-diol levels and/or deficits in $5 \alpha$-reductase metabolism.

The present findings suggest that androgens' effects to enhance cognitive and affective performance may be due to actions of the $5 \alpha$-reduced metabolite, $3 \alpha$-diol. However, T's other metabolites may also have beneficial effects to enhance cognition and affect. For example, $\mathrm{T}$ can be aromatized to estrogen. In women, estrogen levels decline with menopause, which is associated with increased 
incidence of mood disorders and decreased performance in visuospatial tasks (Miller et al., 2002). In animals, estrogen administration increases cognitive performance and decreases anxiety behavior of young and aged female rodents (Frick et al., 2002; Markham et al., 2002; Gresack and Frick, 2006; Walf et al., 2009; Walf and Frye, 2010). Thus, T's effects to enhance cognitive and affective behavior may be due, in part, to estrogen. However, cognitive deficits associated with normal aging or $\mathrm{AD}$ are associated with decreased levels of androgens, but not estrogen (Rosario et al., 2010). Aromatase knockout mice, which lack the enzyme necessary to convert $\mathrm{T}$ to estrogen and thus have very low endogenous estrogen levels, exhibit normal affective behavior (Dalla et al., 2005). In the present study, $\mathrm{E}_{2}$ levels were not consistently elevated in animals that showed enhanced behavior in cognitive and affective tasks. Only administration of the nonaromatizable metabolite $3 \alpha$-diol, was consistently effective at enhancing behavior across tasks. It is also possible that T's beneficial effects are due to actions of DHT. Administration of DHT can enhance cognitive and affective behavior of male rodents (Edinger and Frye, 2004; Edinger et al., 2004). However, DHT's effects are inconsistent across tasks. Additionally, in the present study, DHT levels were not consistently elevated in animals that displayed enhanced behavior. Together, these findings suggest that androgens may have effects to enhance cognitive and affective behavior of aged male rats through actions of T's nonaromatizable metabolite, $3 \alpha$-diol.

It is possible that age-related deficits in performance may be due to differences in stress responses. Older rats have higher and longer-lasting stress-induced corticosterone responses than do younger rats (Sapolsky et al., 1983), which may influence cognitive performance. Twenty-three- to 28 -month-old male rats that have impaired performance in the water maze have higher levels of corticosterone than do rats of the same age that do not have impaired performance, or 6-month-old rats (Lorens et al., 1990). Sex differences in stress-induced changes in cognitive performance are reduced in aged compared to young adult rats (Hodes and Shors, 2005). Additionally, mice with the testicular feminization mutation (Tfm) that lack functional androgen receptors (ARs) have increased plasma corticosterone levels (Zuloaga et al., 2008). However, in the present study, basal corticosterone levels were not significantly different as a result of age or hormone condition at the time point sampled. Due to limitations in tissues collected, the present study was not able to look at corticosterone levels in aged animals that were administered $3 \alpha$-diol in order to determine the impact of this metabolite on stress responses. There were no differences in flinch/jump response to shock in the defensive freezing or inhibitory avoidance tasks, indicating that different ages and/or androgen conditions did not experience differences in the perception of this task. Another study reported similarities in flinch-jump responding of young and aged Fischer-344 rats (Vasquez et al., 1983). The relationship between age-associated deficits in performance and stress is an area of research that will need to be more thoroughly investigated.

The possibility that age-related deficits in performance may be due to differences in visual and motor performance among aged rats needs to be considered. In future studies, a cued trial with a visible platform in the Morris Water maze task would allow us to make determinations about differences in visual acuity among rats across these different age groups, but this potential confound could not be addressed in the present study because this type of trial was not done. In this task, differences in swim speed due to age must also be considered in interpretation of the water maze results. Differences in swim speed were only noted during the testing trial in Experiment 1 and not during training in any of the Experiments or during testing in Experiments 2 and 3. Although we did not see clear differences in swim speed across all training or testing trials, younger, GDX and T-replaced rats clearly had the fastest swim speeds in Experiment 1, which needs to be taken into account in light of the fact that this group also have lower latencies to find the platform in this task. These swim speed data do not entirely control for age effects in the water maze, but this pattern across three experiments suggest that not all effects are due to differences in rats' abilities to swim. Although the results in the water maze have these caveats to consider, the present study addresses age and androgen-related effects in other tasks to more fully address the research question on the role of androgen metabolites in aging for functional effects. Indeed, to address other age-related factors in interpretation of the present results, we have investigated whether there were clear differences in training parameters across two learning tasks, the inhibitory avoidance and water maze. We found that differences in training latencies for the inhibitory avoidance and water maze tasks, and distances swam during training, which used various training stimuli, were not consistently different across experiments. Additionally, although Experiment 1 showed differences in swimming in the forced swim task dependent on age, these differences were not consistent across experiments. However, it must be noted that results obtained in Experiment 2 must be carefully considered because there was a small number of observations per group. Additionally, no clear and consistent effects of age or hormone status for responses to shock stimuli in the inhibitory avoidance and defensive freezing tasks, as measured by flinch-jump ratings, were observed. Further, duration burying in response to shock in the defensive freezing task was not different across age groups, indicating that age-associated differences in motor behavior may have been minimal. Together, these data suggest that not all differences in cognitive or affective performance were due to physical abilities or sensitivities that may differ with age and/or hormone status, but that additional studies that could address these factors more systematically would be useful.

There are multiple receptor substrates through which androgens may exert their beneficial effects. T and DHT bind with high affinity to ARs; whereas, $3 \alpha$-diol has actions at $\mathrm{GABA}_{\mathrm{A}}$ receptors (GBRs; Roselli et al., 1987; Frye et al., 1996a,b) or at estrogen receptor (ER)- $\beta$ in the hippocampus (Kaminski et al., 2005; Pak et al., 2005; Edinger and Frye, 2007). Intrahippocampal administration of flutamide, an AR antagonist, decreases cognitive performance (Edinger and Frye, 2007) and increases anxiety behavior (Edinger and Frye, 2006) of gonadally-intact and DHT-replaced rats. Further, Tfm mice, which lack functional ARs, demonstrate increased anxiety in the novel object and light/dark transition tasks. However, Tfm mice did not consistently show increased anxiety in the open field or elevated plus maze tasks (Zuloaga et al., 2008), indicating that another mechanism may be responsible for some of androgens' beneficial effects. A future question is the extent to which $3 \alpha$-diol's effects in aged rats may be due to actions at GABA, ER $\beta$, or other novel steroid targets. 
Androgens' effects to enhance cognitive and affective performance in aged rats may take place through their effects to enhance neurogenesis. Some anti-depressants exert their beneficial effects on mood and affect by altering neurogenesis. For example, it has been demonstrated that fluoxetine can increase neurogenesis in the hippocampus (Malberg et al., 2000; Santarelli et al., 2003). There is also evidence that androgens can exert neurogenic effects. Male voles with high $\mathrm{T}$ levels have elevated hippocampal neurogenesis compared to voles with low T levels (Spritzer et al., 2004). In young rats, administration of $\mathrm{T}$ and/or $3 \alpha$-diol prevents against adrenalectomy- or GDX-induced deficits in inhibitory avoidance performance and neurodegeneration in the granule cell layer of the dentate (Frye and McCormick, 2000a,b; Spritzer and Galea, 2007; Spritzer et al., 2008) and can increase neurogenesis in the hippocampus (Kovacs et al., 2003; Leranth et al., 2003, 2004; MacLusky et al., 2004, 2006). Among young rats, enhanced neurogenesis is associated with better cognitive performance (Shors et al., 2002). Aged rodents demonstrate decreased neurogenesis in the hippocampus (Kuhn et al., 1996; Erickson and Barnes, 2003), which corresponds to deficits in conditioned fear testing (Wati et al., 2006). Thus, this is an area of research regarding androgens' effects and mechanisms that need to be further investigated.

\section{REFERENCES}

Adler, A., Vescovo, P., Robinson, J. K., and Kritzer M. F. (1999). Gonadectomy in adult life increases tyrosine hydroxylase immunoreactivity in the prefrontal cortex and decreases open field activity in male mice. Neuroscience 89, 939-954.

Alexander, G. M., Swerdloff, R. S., Wang, C., Davidson, T., McDonald, V., Steiner, B., and Hines, M. (1983). Androgenbehavior correlations in hypogonadal men and eugonadal men. II. Cognitive abilities. Horm. Behav. 33, 85-94.

Almeida, O. P., Waterreus, A., Spry, N., Flicker, L., and Martins, R. N. (2004). One year follow-up study of the association between chemical castration, sex hormones, $\beta$ amyloid, memory and depression in men. Psychoneuroendocrinology 9 , 1071-1081.

Ando, S., and Ohashi, Y. (1991). Longitudinal study on age-related changes of working and reference memory in the rat. Neurosci. Lett. 128, 17-20.

Aubele, T., Kaufman, R., Montalmant, F., and Kritzer, M. F. (2008). Effects of gonadectomy and hormone replacement on a spontaneous novel object recognition task in adult male rats. Horm. Behav. 54, 244-252.

Barnes, C.A. (1979). Memory deficits associated with senescence: a neurophysiological and behavioral study in the rat. J. Comp. Physiol. Psychol. 93, 74-104.

Beer, T. M., Bland, L. B., Bussiere, J. R., Neiss, M.B., Wersinger, E.M., Garzotto, M., Ryan, C. W., and Janowsky, J. S.
(2006). Testosterone loss and estradiol administration modify memory in men. J. Urol. 175,130-135.

Benice, T. S., and Raber, J. (2009). Testosterone and dihydrotestosterone differentially improve cognition in aged female mice. Learn. Mem. 16, 479-485.

Bennett, J. C., McRae, P. A., Levy, L. J., and Frick, K. M. (2006). Long-term continuous, but not daily, environmental enrichment reduces spatial memory decline in aged male mice. Neurobiol. Learn. Mem. 85, 139-152.

Bimonte-Nelson, H. A., Singleton, R. S., Nelson, M. E., Eckman, C. B., Barber, J., Scott, T. Y., and Granholm, A. C. (2003). Testosterone, but not nonaromatizable dihydrotestosterone, improves working memory and alters nerve growth factor levels in aged male rats. Exp. Neurol. 181, 301-312.

Bing, O., Heilig, M., Kakoulidis, P., Sundblad, C., Wikland, L., and Eriksson, E. (1998). High doses of testosterone increase anti-conflict behavior in rat. Eur. Neuropsychopharmacol. 8, 321-323.

Bitran, D., Kellog, C. K., and Hilvers, anabolic-androgenic steroid affects anxiety-related behavior and alters the sensitivity of cortical GABAA receptors in the rat. Horm. Behav. 27, 568-583.

Butler, S. S. (2006). Evaluating the senior companion program a mixed-method approach. J. Gerontol. Soc. Work 47, 45-70. R. J. (1993). Treatment with an

In summary, the present data demonstrate that aged rodents have androgen decline and decrements in cognitive and affective performance. Some of these decrements can be improved through systemic administration of the non-aromatizable metabolite, $3 \alpha-$ diol. Additionally, only androgen milieu that were effective at producing beneficial effects on behavior consistently elevated $3 \alpha$-diol levels in the hippocampus in young and aged rats. Together, these findings suggest that some aging-related decrements in cognitive and affective behaviors may be related to decline in production of the T metabolite, $3 \alpha$-diol. Given the aging population, it is particularly important to further investigate the mechanisms and brain targets of androgens' effects in aging individuals.

\section{ACKNOWLEDGMENTS}

Studies described were supported by grants to CAF from the National Institute of Mental Health (MH06769801), National Science Foundation (IBN03-16083), a pilot grant from the National Institute on Aging, the intramural Faculty Research Award Program grant from University at Albany-SUNY and to EDL from the USDA (2004-01811). Assistance, provided by Dr. Madeline Rhodes, Jeffrey Duquette, and Kanako Sumida, in the behavioral and radioimmunoassay analyses, is greatly appreciated.

Cafri, G., van den Berg, P., and Thompson, J. K. (2006). Pursuit of muscularity in adolescent boys: relations among biopsychosocial variables and clinical outcomes. J. Clin. Child Adolesc. Psychol. 35, 283-291.

Ceccareli, I., Scaramuzzino, A., and Aloisi, A. M. (2001). Effects of gonadal hormones and persist pain on non-spatial working memory in male and female rats. Behav. Brain Res. 123, 65-76.

Chambers, K. C., and Phoenix, C. H. (1984). Testosterone and the decline of sexual behavior in aging male rats. Behav. Neural Biol. 40, 87-97.

Cherrier, M. M., Anawalt, B. D., Herbst, K. L., Amory, J. K., Craft, S., Matsumoto, A. M., and Bremner, W. J. (2002). Cognitive effects of short-term manipulation of serum sex steroids in healthy young men. J. Clin. Endocrinol. Metab. 87, 3090-3096.

Clark, C. R., Paul, R. H., Williams, L. M., Arns, M., Fallahpour, K., Handmer, C., and Gordon, E. (2006). Standardized assessment of cognitive functioning during development and aging using an automated touchscreen battery. Arch. Clin. Neuropsychol. 21, 449-446.

Colombo, P. J., and Gallagher, M. (1998). Individual differences in spatial memory and striatal ChAT activity among young and aged rats. Neurobiol. Learn. Mem. 70, 314-327.

Dalla, C., Antoniou, K., PapadopoulouDaifoti, Z., Balthazart, J., and Bakker, J. (2005). Male aromatase-knockout mice exhibit normal levels of activity, anxiety and 'depressive-like' symp- tomatology. Behav. Brain Res. 163, 186-193.

Daniel,J.M.(2006). Effects of oestrogen on cognition: what have we learned from basic research? J. Neuroendocrinol. 8, 787-795.

Daniel, J. M., Fader, A. J., Spencer, A. L., and Dohanich, G. P. (1997). Estrogen enhances performance of female rats during acquisition of a radial arm maze. Horm. Behav. 32, 217-225.

Daniel, J. M., Hulst, J. L., and Berbling, J. L. (2006). Estradiol replacement enhances working memory in middleaged rats when initiated immediately after ovariectomy but not after a long-term period of ovarian hormone deprivation. Endocrinology 147, 607-614.

Davis, S. (2001) Testosterone deficiency in women. J. Reprod. Med. 46, 291-296.

Delhez, M., Hansenne, M., and Legros, J. J. (2003)Andropause and psychopathology: minor symptoms rather than pathological ones. Psychoneuroendocrinology 28, 863-874.

Drake, E. B., Henderson, V. W., Stanczyk, F. Z., McCleary, C. A., Brown, W. S., Smith, C. A., Rizzo, A. A., Murdock, G. A., and Buckwalter, J. G. (2000). Associations between circulating sex steroid hormones and cognition in normal elderly women. Neurology 54, 599-603.

Driscoll, I., Howard, S. R., Stone, J. C., Monfils, M. H., Tomanek, B., Brooks, W. M., and Sutherland, R. J. (2006). The aging hippocampus: a multi-level analysis in the rat. Neuroscience 139, 1173-1185. 
Edinger, K. L., and Frye, C. A. (2004). Testosterone's analgesic, anxiolytic, and cognitive-enhancing effects may be due in part to actions of its $5 \alpha$-reduced metabolites in the hippocampus. Behav. Neurosci. 118, 1352-1136.

Edinger, K. L., and Frye, C. A. (2005). Testosterone's anti-anxiety and analgesic effects may be due in part to actions of its $5 \alpha$-reduced metabolites in the hippocampus. Psychoneuroendocrinology 30, 418-430.

Edinger, K. L., and Frye, C. A. (2006). Intrahippocampal administration of an androgen receptor antagonist, flutamide, can increase anxiety-like behavior in intact and DHT-replaced male rats. Horm. Behav. 50, 216-222.

Edinger, K. L., and Frye, C. A. (2007). Androgens effects to enhance learning and memory may be mediated in part by actions at estrogen receptor- $\beta$ in the hippocampus. Neurobiol. Learn. Mem. 87, 78-85.

Edinger, K. L., Lee, B., and Frye, C. A. (2004). Mnemonic effects of testosterone and its $5 \alpha$-reduced metabolites in the conditioned Fear and inhibitory avoidance tasks. Pharmacol. Biochem. Behav. 78, 559-568.

Erickson, C. A., and Barnes, C. A. (2003). The neurobiology of memory changes in normal aging. Exp. Gerontol. 38, 61-69.

Fernandez-Guasti,A., and Martinez-Mota, L. (2003). Orchidectomy sensitizes male rats to the action of diazepam on burying behavior latency: role of testosterone. Pharmacol. Biochem. Behav. 75, 473-479.

Foster, T. C., and Kumar, A. (2007). Susceptibility to induction of longterm depression is associated with impaired memory in aged Fischer 344 rats. Neurobiol. Learn. Mem. 87, 522-535.

Foster, T. C., Sharrow, K. M., Kumar, A., and Masse, J. (2003). Interaction of age and chronic estradiol replacement on memory and markers of brain aging. Neurobiol. Aging 24, 839-852.

Freedland, S. J., Eastham, J., and Shore, N. (2009). Androgen deprivation therapy and estrogen deficiency induced adverse effects in the treatment of prostate cancer. Prostate Cancer Prostatic Dis. 12, 333-338.

Frick, K. M., Fernandez, S. M., and Bulinski, S. C. (2002). Estrogen replacement improves spatial reference memory and increases hippocampal synatophysin in aged female mice. Neuroscience 115, 547-558.

Frye, C. A., and Bayon, L. E. (1999). Mating stimuli influence endogenous variations in the neurosteroids $3 \alpha, 5 \alpha$ -
THP and $3 \alpha$-Diol. J. Neuroendocrinol. 11, 839-847.

Frye, C. A., Edinger, K., and Sumida, K. (2008). Androgen administration to aged male mice increases anti-anxiety behavior and enhances cognitive performance. Neuropsychopharmacology 33, 1049-1061.

Frye, C. A., and Edinger, K. L. (2004). Testosterone's metabolism in the hippocampus may mediate its antianxiety effects in male rats. Pharmacol. Biochem. Behav. 78, 473-481.

Frye, C. A., Edinger, K. L., Seliga, A. M., and Wawrzycki, J. M. (2004). $5 \alpha$ reduced androgens may have actions in the hippocampus to enhance cognitive performance of male rats. Psychoneuroendocrinology 29, 1019-1027.

Frye, C. A., and Lacey, E. H. (2001). Posttraining androgens' enhancement of cognitive performance is temporally distinct from androgens' increases in affective behavior. Cogn. Affect. Behav. Neurosci. 1, 172-182.

Frye, C.A., and McCormick, C.M. (2000a). Androgens are neuroprotective in the dentate gyrus of adrenalectomized female rats. Stress 3, 185-194.

Frye, C. A., and McCormick, C. M. (2000b). The neurosteroid, $3 \alpha$ androstanediol, prevents inhibitory avoidance deficits and pyknotic cells in the granule layer of the dentate gyrus induced by adrenelectomy in rats. Brain Res. 855, 166-170.

Frye, C. A., Park, D., Tanaka, M., Rosellini, R., and Svare, B. (2001). The testosterone metabolite and neurosteroid $3 \alpha$ - and androstanediol may mediate the effects of testosterone on conditioned place preference. Psychoneuroendocrinology 26, 731-750.

Frye, C. A., Petralia, S. M., and Rhodes, M. E. (2000). Estrous cycle and sex differences in performance on anxiety tasks coincide with increases in hippocampal progesterone and $3 \alpha, 5 \alpha$-THP. Pharmacol. Biochem. Behav. 67, 587-596.

Frye, C. A., and Rhodes, M. E. (2002). Enhancing effects of estrogen on inhibitory avoidance performance may be in part independent of intracellular estrogen receptors in the hippocampus. Brain Res. 956, 285-293.

Frye, C. A., and Seliga, A. M. (2001). Testosterone increases analgesia, anxiolysis, and cognitive performance of male rats. Cogn. Affect. Behav. Neurosci. 1, 371-381.

Frye, C. A., Van Keuren, K. R., and Erskine, M. S. (1996a). Behavioral effects of $3 \alpha$-androstanediol. I: Modulation of sexual receptivity and promotion of GABA-stimulated chloride flux. Behav. Brain Res. 79 , 109-118.

Frye, C. A., Van Keuren, K. R., Rao, P. N., and Erskine, M. S. (1996b). Progesterone and $3 \alpha$-androstanediol conjugated to bovine serum albumin affects estrous behavior when applied to the MBH and PDA. Behav. Neurosci. 110, 603-612.

Frye, C. A., and Walf, A. A. (2009). Progesterone reduces depressionlike behavior in a murine model of Alzheimer's Disease. Age (Omaha) 31, 143-153.

Gage, F. H., Chen, K. S., Buzsaki, G., and Armstrong, D. (1988). Experimental approaches to age-related cognitive impairments. Neurobiol. Aging 9, 645-655.

Galea, L. A., Uban, K. A., Epp, J. R., Brummelte, S., Barha, C. K., Wilson, W. L., Lieblich, S. E., and Pawluski, J. L. (2008). Endocrine regulation of cognition and neuroplasticity: our pursuit to unveil the complex interaction between hormones, the brain, and behaviour. Can. J. Exp. Psychol. 62, 247-260.

Gallagher, M., and Burwell, R. D. (1989) Relationship of age-related decline across several behavioral domains. Neurobiol. Aging 10, 691-708.

Gallagher, M., and Nicolle, M. M. (1993). Animal models of normal aging: relationship between cognitive decline and markers in hippocampal circuitry. Behav. Brain Res. 57, 155-162.

Gibbs, R. B. (2005). Testosterone and estradiol produce different effects on cognitive performance in male rats. Horm Behav. 48, 268-277.

Gibbs, R. B., and Johnson, D. A. (2008) Sex-specific effects of gonadectomy and hormone treatment on acquisition of a 12-arm radial maze task by Sprague Dawley rats. Endocrinology 149, 3176-3183.

Goudsmit, E., Van de Poll, N. E., and Swaab, D. F. (1990). Testosterone fails to reverse spatial memory decline in aged rats and impairs retention in young and middle-aged animals. Behav. Neural Biol. 53, 6-20.

Gray, G.D. (1978). Age-related changes in penile erections and circulating testosterone in middle-aged male rats. $A d v$. Exp. Med. Biol. 113, 149-158.

Gresack, J. E., and Frick, K. M. (2006) Post-training estrogen enhances spatial and object memory consolidation in female mice. Pharmacol. Biochem. Behav. 84, 112-119.

Haren, M. T., Morley, J. E., Chapman, I. M., O'Loughlin, P. D., and Wittert, G. A. (2002). Defining 'relative' androgen deficiency in aging men: how should testosterone be measured and what are the relationships between androgen levels and physical, sexual, and emotional, health. Climacteric 5,15-25

Haren, M. T., Wittert, G. A., Chapman, I. M., Coates, P., and Morley, J. E. (2005). Effect of oral testosterone undecanoate on visuospatial cognition, mood and quality of life in elderly men with lownormal gonadal status. Maturitas 50, 124-133.

Henderson, V. W., Watt, L., and Buckwalter, J. G. (1996). Cognitive skills associated with estrogen replacement in women with Alzheimer's disease. Psychoneuroendocrinology 21, 421-430.

Hodes, G. E., and Shors, T. J. (2005). Distinctive stress effects on learning during puberty. Horm. Behav. 48, 163-171.

Hogervorst, E., Combrinck, M., and Smith, A. D. (2003). Testosterone and gonadotropin levels in men with dementia. Neuro. Endocrinol. Lett. 24 203-208.

Howell, S., and Shalet, S. (2001). Testosterone deficiency and replacement. Horm. Res. 56(Suppl. 1), 86-92.

Howieson, D. B., Holm, L. A., Kaye, J. A., Oken, B. S., and Howieson, J. (1993). Neurologic function in the optimally healthy oldest old Neuropsychological evaluation. Neurology 43, 1882-1886.

Hunter, C. L., Bimonte-Nelson, H. A. Nelson, M., Eckman, C. B., and Granholm, A. C. (2004). Behavioral and neurobiological markers of Alzheimer's disease in Ts65Dn mice: effects of estrogen. Neurobiol. Aging 25, 873-884.

Janowsky, J. S. (2006a). Thinking with your gonads: testosterone and cognition. Trends Cogn. Sci. 10, 77-82.

Janowsky, J.S. (2006b). The role of androgens in cognition and brain aging in men. Neuroscience 138, 1015-1020.

Janowsky, J. S., Chavez, B., and Orwoll, E. (2000). Sex steroids modify working memory. J. Cogn. Neurosci. 12, 407-414.

Janowsky, J. S., Oviatt, S. K., and Orwoll, E. S. (1994). Testosterone influences spatial cognition in older men. Behav. Neurosci. 108, 325-332.

Kaminetsky, J. C. (2005). Benefits of a new testosterone gel formulation for hypogonadal men. Clin. Cornerstone 7(Suppl. 4), S8-S12.

Kaminski, R. M., Marini, H., Kim, W. J., and Rogawski, M. A. (2005). Anticonvulsant activity of androsterone and etiocholanolone. Epilepsia 46, 819-827.

Kasckow, J. W., Segar, T. M., Xiao, C., Furay,A. R., Evanson, N. K., Ostrander, M. M., and Herman, J. P. (2005). 
Stability of neuroendocrine and behavioral responsiveness in aging Fischer 344/Brown-Norway hybrid rats. Endocrinology 146, 3105-3112.

Kawas, C., Resnick, S., Morrison, A., Brookmeyer, R., Corrada, M., Zonderman, A., Bacal, C., Lingle, D.D., and Metter, E. A. (1997). Prospective study of estrogen replacement therapy and the risk of developing Alzheimer's disease: the Baltimore Longitudinal Study of Aging. Neurology 48, 1517-1521.

Kovacs, E. G., MacLusky, N. J., and Leranth, C. (2003). Effects of testosterone on hippocampal CAl spine synaptic density in the male rat are inhibited by fimbria/fornix transection. Neuroscience 122, 807-810.

Kritzer, M. F., Brewer, A., Montalmant, F., Davenport, M., and Robinson, J. K. (2007). Effects of gonadectomy on performance in operant tasks measuring prefrontal cortical function in adult male rats. Horm. Behav. 51, 183-194.

Kuhn, H. G., Dickinson-Anson, H., and Gage, F. H. (1996). Neurogenesis in the dentate gyrus of the adult rat: age-related decrease of neuronal progenitor proliferation. J. Neurosci. 16, 2027-2033.

Lephart,E.D.,Andersson, S., and Simpson, E. R. (1990). Expression of neural $5 \alpha$ reductase messenger ribonucleic acid: comparison to $5 \alpha$-reductase activity during prenatal development in the rat. Endocrinology 127, 1121-1128.

Lephart, E. D., Lund, T. D., and Horvath, T. A. (2001). Brain androgen and progesterone metabolizing enzymes: biosynthesis, distribution, and function. Brain Res. Rev. 37, 25-37.

Lephart, E. D., and Ojeda, S. R. (1990). Hypothalamic aromatase activity in male and female rats during juvenile peripubertal development. Neuroendocrinology 51, 385-393.

Leranth, C., Hajszan, T., and MacLusky, N. J. (2004). Androgens increase spine synapse density in the CAl hippocampal subfield of ovariectomized female rats. J. Neurosci. 24, 495-499.

Leranth, C., Petnehazy, O., and MacLusky, N. J. (2003). Gonadal hormones affect spine synaptic density in the CA1 hippocampal subfield of male rats. J. Neurosci. 23, 1588-1592.

Li, J. Y., Zhu, J. C., Dou, J. T., Bai, W. J., Deng, S. M., Li, M., Huang, W., and Jin, H. (2002). Effects of androgen supplementation therapy on partial androgen deficiency in the aging male: a preliminary study. Aging Male 5, 47-51.

Light, L. L. (1991). Memory and aging: four hypotheses in search of data. Annu. Rev. Psychol. 42, 333-376.
Lorens, S. A., Hata, N., Handa, R. J., Van de Kar, L. D., Guschwan, M., Goral, J., Lee, J. M., Hamilton, M. E., Bethea, C. L., and Clancy, J. Jr. (1990). Neurochemical, endocrine and immunological responses to stress in young and old Fischer 344 male rats. Neurobiol. Aging 11, 139-150.

Luine, V.N. (2008). Sex steroids, and cognitive function. J. Neuroendocrinol. 20, 866.

Lund, B. C., Bever-Stille, K. A., and Perry, P. J. (1999). Testosterone and andropause: the feasibility of testosterone replacement therapy in elderly men. Pharmacotherapy 19, 951-956.

MacLusky, N. J., Hajszan, T., and Leranth, C. (2004). Effects of dehydroepiandrosterone and flutamide on hippocampal CA1 spine synapse density in male and female rats: implications for the role of androgens in maintenance of hippocampal structure. Endocrinology 145, 4154-4161.

MacLusky, N. J., Hajszan, T., Prange-Kiel, J., and Leranth, C. (2006). Androgen modulation of hippocampal synaptic plasticity. Neuroscience 138, 957-965.

Malberg, J.E., Eisch, A. J., Nestler, E. J., and Duman, R. S. (2000). Chronic antidepressant treatment increases neurogenesis in adult rat hippocampus. $J$. Neurosci. 20, 9104-9110.

Markham, J. A., Pych, J. C., and Juraska, J. M. (2002). Ovarian hormone replacement to aged ovariectomized female rats benefits acquisition of the morris water maze. Horm. Behav. 42, 284-293.

Markou, A., Duka, T., and Prelevic, G. M. (2004). Estrogens and brain function. Hormones 4, 9-17.

Markowska, A. L., and Savonenko, A. V. (2002). Effectiveness of estrogen replacement in restoration of cognitive function after long-term estrogen withdrawal in aging rats. J. Neurosci. 22, 10985-10995.

Miller, K. J., Conney, J. C., Rasgon, N. L., Fairbanks, L. A., and Small, G. W. (2002). Mood symptoms and cognitive performance in women estrogen users and nonusers and men. J. Am. Geriatr. Soc. 50, 1826-1830.

Moffat, S. D., Zonderman, A. B., Metter, E. J., Kawas, C., Blackman, M. R., Harman, S. M., and Resnick, S. M. (2002). Longitudinal assessment of serum free testosterone concentration predicts memory performance and cognitive status in elderly men. J. Clin. Endocrinol. Metab. 87, 5001-5007.

Mohaddes, G., Naghdi, N., Khamnei, S., Khatami, S., and Haeri, A. (2009). Effect of spatial learning on hippocampal testosterone in intact and castrated male rats. Iran Biomed. J. $13,49-58$.
Naghdi, N., Oryan, S., and Etemadi, R. (2003). The study of spatial memory in adult male rats with injection of testosterone ethanate and flutamide into the basolateral nucleus of the amygdala in the Morris Water maze. Brain Res. 972, 1-8.

Nathorst-Boos, J., von Schoultz, B., and Carlstrom, K. (1993). Elective ovarian removal and estrogen replacement therapy effects on sexual life, psychological well-being and androgen status. J. Psychosom. Obstet. Gynaecol. 14, 283-293.

O'Connor, D. B., Archer, J., Hair, W. M. and Wu, F. C. (2001). Activational effects of testosterone on cognitive function in men. Neuropsychologia 39, 1385-1394.

Orengo, C. A., Fullerton, G., and Tan, R. (2004). Male depression: a review of gender concerns and testosterone therapy. Geriatrics 59, 24-30.

Pak, T.R., Chung, W.C., Lund, T.D., Hinds, L. R., Clay, C.M., and Handa, R.J.(2005). The androgen metabolite, $5 \alpha$-androstane- $3 \beta, 17 \beta$-diol, is a potent modulator of estrogen receptor- $\beta 1$-mediated gene transcription in neuronal cells. Endocrinology 146, 147-155.

Palermo-Neto, J., and Dorce, V.A. (1990). Influences of estrogen and/or progesterone on some dopamine-related behavior in rats. Gen. Pharmacol. 21 , 83-87.

Pearlstein, T., Rosen, K., and Stone, A. B. (1997). Mood disorders and menopause. Endocrinol. Metab. Clin. North Am. 26, 279-294.

Pettersson, H., Lundqvist, J., Oliw, E., and Norlin, M. (2009).CYP7B1-mediated metabolism of $5 \alpha$-androstane- $3 \alpha, 17 \beta$ diol ( $3 \alpha$-Adiol): A novel pathway for potential regulation of the cellular levels of androgens and neurosteroids. Biochim. Biophys. Acta 1791, 1206-1215.

Pike, C. J., Nguyen, T. V., Ramsden, M., Yao, M., Murphy, M. P., and Rosario, E. R. (2008). Androgen cell signaling pathways involved in neuroprotective actions. Horm. Behav. 53, 693-705.

Pike, K.E., and Savage, G. (2008). Memory profiling in mild cognitive impairment: can we determine risk for Alzheimer's disease? J. Neuropsychol. 2, 361-372.

Pisarska, M., Mulchahey, J. J., Welge, J. A., Geracioti, T. D. Jr, and Kasckow, J. W. (2000). Age-related alterations in emotional behaviors and amygdalar corticotropin-releasing factor (CRF) and CRF-binding protein expression in aged Fischer 344 rats. Brain Res. 877 , 184-190.

Raber, J. (2004). Androgens, apoE, and Alzheimer's disease. Sci. Aging Knowledge Environ. 17, 2004(11):re2.
Raber, J. (2008). AR, apoE, and cognitive function. Horm. Behav. 53, 706-715.

Rosario, E. R., Carroll, J. C., Oddo, S., LaFerla, F. M., and Pike, C. J. (2006). Androgens regulate the development of neuropathology in a triple transgenic mouse model of Alzheimer's disease. J. Neurosci. 26, 13384-13389.

Rosario, E.RosarioR., Chang, L., Beckett, T. L., Carroll, J. C., Paul Murphy, M., Stanczyk, F. Z., and Pike, C. J. (2009). Age-related changes in serum and brain levels of androgens in male Brown Norway rats. Neuroreport 20, 1534-1537.

Rosario, E. R., Chang, L., Head, E. H., Stanczyk, F. Z., and Pike, C. J. (2010). Brain levels of sex steroid hormones in men and women during normal aging and in Alzheimer's disease. Neurobiol. Aging. (In press)

Rosario, E. R., and Pike, C. J. (2008). Androgen regulation of $\beta$-amyloid protein and the risk of Alzheimer's disease. Brain Res. Rev. 57, 444-453.

Roselli, C. E., Horton, L. E., and Resko, J. A. (1987). Time-course and steroid specificity of aromatase induction in rat hypothalamus-preoptic area. Biol. Reprod. 37, 628-633.

Rosenbaum, R. S., Winocur, G., Grady, C. L., Ziegler, M., and Moscovitch, M. (2007). Memory for familiar environments learned in the remote past: fMRI studies of healthy people and an amnesic person with extensive bilateral hippocampal lesions. Hippocampus 17, 1241-1251.

Sandstrom, N. J., Kim, J. H., and Wasserman,M.A. (2006). Testosterone modulates performance on a spatial working memory task in male rats. Horm. Behav. 50, 18-26.

Sandstrom, N. J., and Williams, C. L. (2001). Memory retention is modulated by acute estradiol and progesterone replacement. Behav. Neurosci. $115,384-393$.

Sandstrom, N. J., and Williams, C. L. (2004). Spatial memory retention is enhanced by acute and continuous estradiol replacement. Horm. Behav. $45,128-135$.

Santarelli, L., Saxe, M., Gross, C., Surget,A., Battaglia, F., Dulawa, S., Weisstaub, N., Lee,J.,Duman, R.,Arancio, O., Belzung, C., and Hen, R. (2003). Requirement of hippocampal neurogenesis for the behavioral effects of antidepressants. Science 301, 805-809.

Sapolsky, R. M., Krey, L. C., and McEwen, B.S. (1983). The adrenocortical stressresponse in the aged male rat: impairment of recovery from stress. Exp. Gerontol. 18, 55-64.

Savonenko, A. V., and Markowska, A. L. (2003). The cognitive effects of ova- 
riectomy and estrogen replacement are modulated by aging. Neuroscience 119, 821-830.

Schaeffer, V, Patte-Mensah, C., Eckert, A., and Mensah-Nyagan, A. G. (2006). Modulation of neurosteroid production in human neuroblastoma cells by Alzheimer's disease key proteins. J. Neurobiol. 66, 868-881.

Seidman, S. N. (2003). Testosterone deficiency and mood in aging men: pathogenic and therapeutic interactions. World J. Biol. Psychiatry 4, 14-20.

Sherwin, B. B. (2002). Estrogen and cognitive aging in women. Trends Pharmacol. Sci. 23, 527-534.

Shors, T. J., Townsend, D. A., Zhao, M., Kozorovitskiy, Y., and Gould, E. (2002). Neurogenesis may relate to some but not all types of hippocampaldependent learning. Hippocampus 12, 578-584.

Shukitt-Hale, B., Mouzakis, G., and Joseph, J.A. (1998). Psychomotor and spatial memory performance in aging male Fischer 344 rats. Exp. Gerontol. 33, 615-624.

Spinar, J., Ludka, O., Senkyríková, M., Vítovec, J., Spinarová, L., and Dusek, L. (2009). [Cholesterol levels according to age] Vnitr Lek. 55, 724-729.

Spritzer, M. D., and Galea, L. A. (2007) Testosterone and dihydrotestosterone, but not estradiol, enhance survival of new hippocampal neurons in adult male rats. Dev. Neurobiol. 67, 1321-1333.

Spritzer, M. D., Gill, M., Weinberg, A. and Galea, L. A. (2008). Castration differentially affects spatial working and reference memory in male rats. Arch. Sex. Behav. 37, 19-29.

Spritzer, M. D., Meikle, D. B., and Solomon, N. G. (2004). The relationship between dominance rank and spatial ability among male meadow voles (Microtus pennsylvanicus). J. Comp. Psychol. 118, 332-339.

Sternbach, H. (1998). Age-associated testosterone decline in men: clinical issues in psychiatry. Am. J. Psychiatry 155, 1310-1318.

Sunderland, T., Mirza, N., Putnam, K. T., Linker, G., Bhupali, D., Durham, R., Soares, H., Kimmel, L., Friedman, D., Bergeson, J., Csako, G., Levy, J. A., Bartko, J. J., and Cohen, R. M. (2004). Cerebrospinal fluid $\beta$-amyloid 1-42 and tau in control subjects at risk for Alzheimer's disease: the effect of APOE epsilon4 allele. Biol. Psychiatry 56, 670-676.

Talboom, J. S., Williams, B. J., Baxley, E. R., West, S. G., and BimonteNelson, H. A. (2008). Higher levels of estradiol replacement correlate with better spatial memory in surgically menopausal young and middleaged rats. Neurobiol. Learn. Mem. 90, 155-163.

Tang, M. X., Jacobs, D., Stern, Y., Marder, K., Schofield, P., Gurland, B., Andrews, H., and Mayeux, R. (1996). Effect of oestrogen during menopause on risk and age at onset of Alzheimer's disease. Lancet 348, 429-432.

Traish, A., Abdou, R., and Kypreos, K. E. (2009). Androgen deficiency and atherosclerosis: The lipid link. Vascul. Pharmacol. 51, 303-313.
Vasquez, B. J., Martinez, J. L. Jr, Jensen, R. A. Messing, R. B., Rigter,H., and McGaugh, J. L. (1983). Learning and memory in young and aged Fischer 344 rats. Arch. Gerontol. Geriatr. 2, 279-291.

Walf, A. A., and Frye, C. A. (2005). ER $\beta$ selective estrogen receptor modulators produce antianxiety behavior when administered systemically to ovariectomized rats. Neuropsychophannacology 30, 1598-1609.

Walf, A. A., and Frye, C. A. (2006). A review and update of mechanisms of estrogen in the hippocampus and amygdala for anxiety and depression behavior. Neuropsychopharmacology 31, 1097-1111.

Walf,A.A., and Frye, C.A. (2010). Estradio reduces anxiety- and depression-like behavior of aged female mice. Physiol. Behav. 99, 169-174.

Walf, A. A., Paris, J. J., and Frye, C. A. (2009). Nociceptive and anxiety-like behavior in reproductively competent and reproductively senescent middle-aged rats. Gend. Med. 6(Suppl. 2), 235-246.

Walf, A. A., Rhodes, M. E., and Frye, C. A. (2004). Antidepressant effects of ER $\beta$-selective estrogen receptor modulators in the forced swim test. Pharmacol. Biochem. Behav. 78, 523-529.

Wallace, M., Luine, V., Arellanos, A., and Frankfurt, M. (2006). Ovariectomized rats show decreased recognition memory and spine density in the hippocampus and prefrontal cortex. Brain Res. 1126, 176-182.

Wati, H., Kudo, K., Qiao, C., Kuroki, T. and Kanba, S. (2006). A decreased survival of proliferated cells in the hippocampus is associated with a decline in spatial memory in aged rats. Neurosci. Lett. 99, 171-174.

Wolf, O. T. (2003). Cognitive functions and sex steroids. Ann. Endocrinol. 64, 158-161.

Zuloaga, D. G., Morris, J. A., Jordan, C. L., and Breedlove, S. M. (2008). Mice with the testicular feminization mutation demonstrate a role for androgen receptors in the regulation of anxiety-related behaviors and the hypothalamic-pituitary-adrenal axis. Horm. Behav. 54, 758-766.

Conflict of Interest Statement: The authors declare that the research was conducted in the absence of any commercial or financial relationships that could be construed as a potential conflict of interest.

Received: 06 November 2009; paper pending published: 25 November 2009; accepted: 16 March 2010; published online: 08 April 2010.

Citation: Frye CA, Edinger KL, Lephart ED and WalfAA (2010) $3 \alpha$-androstanediol, but not testosterone, attenuates age-related decrements in cognitive, anxiety, and depressive behavior of male rats. Front. Ag. Neurosci. 2:15. doi: 10.3389/fnagi.2010.00015

Copyright (C) 2010 Frye, Edinger, Lephart and Walf. This is an open-access article subject to an exclusive license agreement between the authors and the Frontiers Research Foundation, which permits unrestricted use, distribution, and reproduction in any medium, provided the original authors and source are credited. 